\title{
The impact of slow steaming on the carriers' and shippers' costs: The case of a global logistics network
}

\author{
Ioannis Mallidis $^{\mathrm{a}, *}$, Eleftherios Iakovou ${ }^{\mathrm{b}}$, Rommert Dekker ${ }^{\mathrm{c}}$, Dimitrios Vlachos ${ }^{\mathrm{a}}$ \\ a Department of Mechanical Engineering, Aristotle University of Thessaloniki, P.O. Box 461, 54124 Thessaloniki, Greece \\ ${ }^{\mathrm{b}}$ Department of Engineering Technology and Industrial Distribution, Texas A\&M University, College Station, TX 77843, USA \\ ${ }^{\mathrm{c}}$ Econometric Institute, Erasmus University Rotterdam, Burg. Oudlaan 50, 3062 PA Rotterdam, The Netherlands
}

\section{A R T I C L E I N F O}

\section{Keywords:}

Slow steaming

Speed adjustment

Shipper

Carrier

\begin{abstract}
A B S T R A C T
We propose an analytical modeling methodology for quantifying the impact of slow steaming on the carrier's voyage cost and on the shipper's total landed logistics costs. The developed methodology can be employed by a carrier and a shipper in their contract negotiations, in order for the two parties to determine how they could divide between them the savings resulted from slow steaming. We demonstrate that the impact of slow steaming and speed adjustment policies on the shippers' total landed logistics costs tend to increase as the vessel travels towards the end of its voyage.
\end{abstract}

\section{Introduction}

The world fleet grew by 3.5\% throughout 2015. This is the lowest growth rate since 2003, yet still higher than the $2.1 \%$ growth in demand, leading to a continued state of global overcapacity (UNCTAD, 2016). Tracking this trend in time, in 2008 orders for bulk carriers reached more than six times the average of the orders placed in the period between 1980 and 2006, indicating that the shipping sector was at the peak of its economic cycle and its subsequent downfall was imminent (Haralambides and Thanopoulou, 2014). However, despite this alarming indicator, ship owners continued placing orders for the production of new vessels. To that effect, for the 2007-2008 period and even though ship prices were at their peak, $\$ 400$ billion worth of additional ship orders were placed (Stopford, 2010; UNCTAD, 2013).

As the U.S. banking crisis of 2008 led to a global recession and a downturn of global trade, a significant surplus of ship capacity had already been built, further exacerbated as preceding ship orders were being manufactured and new ships entered the market (Haralambides and Thanopoulou, 2014).

In this troublesome environment, carriers face two critical bottlenecks. The first one involves the reduction of their ship-operating costs in order to sustain their profitability and market share in a market with low recovery rates of global demand (UNCTAD, 2013). The second one involves the utilization of their excess idle vessel capacity, due to the global transport demand downturn. This has been a stagnant problem for the shipping industry affecting negatively the level of the ocean freight rates charged to shippers (Wu, 2009).

Under this context, carriers adopt the practice of slow steaming, which involves the reduction of their vessels' speed for reducing fuel consumption (Sanguri, 2012). As fuel costs represent as much as 50-60\% of total vessel voyage costs (World Shipping Council, 2008), it is interesting to state that the increase of a vessel's speed by a couple of knots, that is from 17 to 19 knots, $20-22 \mathrm{knots}$ and 23-25 knots, leads to the consumption of almost 50\% more fuel per unit of distance travelled (Lee et al. 2015). Thus, slow steaming

\footnotetext{
* Corresponding author.

E-mail address: imallidi@auth.gr (I. Mallidis).
} 
provides significant potential for voyage cost reductions. Moreover, as the employment of slow steaming prolongs the ship's voyage duration, and since container demand is accumulated during the extended voyage duration, carriers have the flexibility to incorporate their idle ship capacity in their serving routes in order to improve delivery efficiency (Maloni et al., 2013).

Furthermore, under layday clauses, carriers must reach a port of loading till a predefined time schedule (Raunek, 2015), while during the vessel's voyage, delays may occur due to adverse weather conditions as the vessel sails, or at ports and canals due to congestion and port inefficiencies. On this basis, slow steaming provides carriers with the flexibility to increase their sailing speeds after a delay occurs in order to cover all or as much of the delay possible in order to meet the layday.

To that effect, the employment of slow steaming under speed adjustment can have the following cost implications for the carrier: (i) reductions of voyage fuel costs; and (ii) increases of operating costs as the duration of the voyage increases.

With respect to the shipper, the employment of slow steaming under a vessel's speed adjustment policy may lead to: (i) lower safety stock holding costs, as the carrier's speed adjustment reduces the variability of the shipper's lead-times, and (ii) increases of the shipper's pipeline inventory holding, cycle stock, and backorder costs as the lead-time of order replenishments increases. As the leadtimes also increase, when the voyage distances increase, it is intuitively sound that these cost impacts also depend on the voyage distance that the carrier must cover in order to replenish the shipper's orders. Thus, long voyage distances lead to higher shipper's pipeline and cycle stock costs, but they also provide more flexibility to the carrier to compensate voyage delays by adjusting the vessel's speed, and thus reduce the variability of the shipper's lead-time. It is therefore pivotal to be able to quantify the cost impact of slow steaming on the logistics costs of shippers at all intermediate ports of a shipping network, as the distances travelled by the carrier for replenishing their orders differ.

Under this context, the purpose of this paper is to develop an analytical methodology which provides estimates of the expected cost impacts of slow steaming under speed adjustments for both the carrier and the shipper. This methodology can be employed by the carrier and the shipper in order to quantify the impact of slow steaming on their costs and thus, further be employed for contract negotiations.

To tackle the above, we adopt the following methodological steps as summarized below:

- We estimate the stochastic vessel's voyage duration under various slow steaming speeds, at each intermediate port of a shipping line network, while tackling voyage delays at each intermediate port through higher speed adjustments of the vessel after the delay occurrence.

- We employ the stochastic voyage durations for appropriately selecting the vessel's slow steaming speeds (that lead to similar line efficiency) and further incorporate them in an activity based voyage cost model for estimating the carrier's voyage costs per container till each intermediate port.

- We incorporate the stochastic voyage duration till all intermediate ports and for each slow steaming speed into a continuous review $(\mathrm{Q}, \mathrm{R})$ inventory planning policy; this policy is selected since it provides a better synchronization with the OEM, and allows the estimation of the total landed logistics costs per container of each intermediate port's shipper, while encompassing on-hand and pipeline inventory holding costs, backorder, and facility operating costs.

The contributions of our proposed methodology are listed below:

1. In contrast to the majority of academic research efforts that employ simulation-based methodologies, we develop continuous-time analytical models for capturing the impact of slow steaming on the carrier's and the shipper's costs. We do that by considering a real-world policy used extensively by carriers today, namely the vessel's speed adjustment for recovering voyage delays at intermediate ports of a shipping network.

2. Delays at the intermediate ports of a shipping network are stochastic random variables and are entered in our modelling methodology based on real-world data. The existing research efforts instead, consider predefined distributions of the delay for their modelling purposes. Moreover, the delays considered in our modelling methodology consist of the delays during the voyage and at the ports, in contrast to the majority of the academic research efforts that only consider delays at ports.

3. Our modelling methodology includes specific inventory planning policies, while providing an analytical solution for minimizing the shipper's total landed logistics costs under slow steaming. On the other side, the existing research efforts mainly employ simulation-based methodologies for minimizing the shipper's safety stock and pipeline inventory holding costs.

4. We obtain important managerial insights from the implementation of the developed methodology on a rather extensive realistic case of a shipping line from China to Europe and back to China, while the majority of existing research works employ simple numerical examples.

The rest of the manuscript is organized as follows. In Section 2, we present a critical taxonomy of the existing research efforts encountered in the literature focusing on the application of modelling methodologies for quantifying the impact of slow steaming. Section 3 describes the problem under study, while Section 4 presents the proposed modelling methodology for quantifying the impact of slow steaming on the carriers' and the shippers' logistics costs. More specifically, Sections 4.1 and 4.2 present the modelling methodologies employed for quantifying the impact of slow steaming on the vessel's voyage duration, and for selecting the carrier's appropriate slow steaming speeds respectively. Section 4.3 determines the shipper's cost. Section 4.4 presents the model employed for quantifying the impact of slow steaming on the carrier's costs. Section 5 illustrates the applicability of the proposed modelling methodology through the case study of a global logistics network; it further provides an extensive numerical investigation, while discussing interesting managerial insights. Finally, in Section 6 we sum-up the findings of this research. 


\section{Literature review: a critical taxonomy}

As ocean shipping represents the dominant transportation mode of globalized supply chains (SCs), the cost-effective practice of slow steaming has attracted the interest of numerous researchers, as it leads to the straightforward reduction of the vessel's fuel consumption and thus of its fuel costs (Lee et al., 2015). On this basis, Tezdogan et al. (2014) aim to evaluate the impact of a predefined slow steaming speed on the required effective power and thus the fuel consumption of a deep sea vessel, while considering resistance and motion responses of the vessel. Rahman et al. (2015) employ a Fuzzy Rule-based Bayesian Reasoning method for justifying the necessity of the employment of a super slow steaming speed for voyage cost minimization.

In contrast to the above research efforts, which evaluate the impact of predefined slow steaming speeds on the carrier's voyage costs, numerous research efforts consider the slow steaming speed as a decision variable, and thus, they propose speed optimization algorithms for determining the optimal slow steaming speed that minimizes the vessel's voyage costs. On this basis, Corbett et al. (2009) propose a ship speed optimization model that maximizes the carrier's voyage profitability, and minimizes the carrier's voyage $\mathrm{CO}_{2}$ emissions under fuel taxation policies. Lindstad et al. (2011) developed a similar model which additionally considers the resistance developed by the waves in the speed optimization process. Fagerholt et al. (2010) propose a ship speed optimization model that minimizes the fuel consumption in a route, under voyage time window constraints, while Cariou and Cheaitou (2012) determine the optimal ship speed that maximizes the carrier's voyage profitability and minimizes the carrier's voyage $\mathrm{CO}_{2}$ emissions under the fuel tax and the speed limit policies.

Wang and Meng (2012) developed a mixed-integer non-linear programming model in order to determine: (i) the optimal sailing speed of container ships; (ii) the optimal number of ships to deploy in each route of a liner-shipping network; and (iii) the optimal number of containers dispatched on each container route, under voyage cost minimization objectives. Chang and Chang (2013) propose an activity-based model in order to determine the optimal vessel's speed and fleet size which minimizes the carrier's voyage costs and derived voyage $\mathrm{CO}_{2}$ emissions. To that effect, they develop the CATCH (cost of averting a ton of $\mathrm{CO}_{2}$ emissions- Equation heating) model for evaluating potential cost and $\mathrm{CO}_{2}$ emissions tradeoffs as speed is reduced. Norlund and Gribkovskaia (2013) propose a ship speed optimization methodology and supply vessel-planning algorithm, in order to minimize the voyage costs and $\mathrm{CO}_{2}$ emissions for serving a number of offshore installations. Similarly, Tai and Lin (2013) developed an activity-based ship speed optimization methodology in order to minimize ship voyage, maneuvering, and port residence $\mathrm{CO}_{2}$ emissions stemming from the adoption of daily frequency and slow steaming.

Chang and Wang (2014) develop a speed optimization model that maximizes the carrier's profitability and minimizes its voyage $\mathrm{CO}_{2}$ emissions under four scenarios: (i) high fuel prices and high charter rates; (ii) high fuel prices and low charter rates; (iii) low fuel prices and high charter rates; (iv) low fuel prices and low charter rates. Wong et al. (2015), propose a multi-objective ship speed optimization methodology, which jointly optimizes a vessel's voyage cost, $\mathrm{CO}_{2}$ emissions, and delays. Fagerholt et al. (2015), propose a Mixed Integer Linear Programming Model (MILP), in order to determine the vessel's optimal slow steaming speed, that minimizes the vessel's fuel costs under the strict limits of emissions control areas (ECAs).

Magirou et al. (2015) propose a dynamic programming formulation for determining the optimal vessel speed which minimizes voyage costs, while operating in the spot market and in a tramp mode. Andersson et al. (2015) propose an integrated MILP model for determining the optimal fleet size and speed of Ro Ro vessels. Wang and Xu (2015) also propose a MILP model, for determining a vessel's optimal ship sailing speed that minimizes ship voyage costs and emissions and for deciding on whether a ship owner should accepts a specific chartering agreement or not. Norlund et al. (2016) develop a simulation-based optimization algorithm for determining optimal vessel speeds under voyage costs and emission minimization objectives. Adland et al. (2017), propose a methodology based on a regression analysis in order to determine the slow steaming speed that a vessel must adopt when entering Environmental Control Areas, while identifying how can this speed be further affected by stricter ECA regulations. Further, Wen et al. (2017) propose a ship routing and speed optimization heuristic branch-and-price algorithm that optimizes the vessel's fuel consumption as a function of payload, the fuel price and in-transit cargo inventory costs.

Finally, Guericke and Tierney, (2015), propose a MILP model for addressing the cargo allocation problem with service levels and speed optimization. Their model can be effectively employed to facilitate negotiations of carriers with terminals, while assisting them to plan berthing times based on the recommended sailing speeds on each leg.

Additionally, under slow steaming the carrier has the flexibility to increase its speed after the realization of a delay during a voyage in order to meet its planned arrival times, and since ports congestion constitutes a significant source of vessel voyage delays, the joint consideration of slow steaming on voyage costs under uncertain port service times, has attracted the interest of few researchers. On this basis, Brouer et al. (2013), propose a mixed integer, vessel schedule recovery model, for compensating port delays, through the employment of a speed adjustment policy. The optimization criteria involve the vessel's voyage costs at given speeds, and the penalties to the carrier incurred from delaying or misconnecting cargo. Lee et al. (2015), propose a Markov Chain methodology for minimizing the ship's voyage costs under slow steaming speed optimization, while jointly evaluating the impact of lower vessel speeds on the delivery reliability provided to shippers, and thus on their safety stock levels. The authors address this, by quantifying the stochastic voyage delays incurred at various predefined intermediate ports of a shipping network, and thus, on the stochastic lead times that the shipper faces. To this end, they evaluate the impact of these delays on the shipper's safety stock level, through a simulation-based optimization methodology.

Furthermore, Song et al. (2015) propose a simulation-based non-dominated sorting genetic algorithm, in order to determine a vessel's maximum sailing speed and liner delivery schedule, under voyage cost, service reliability and voyage emissions optimization objectives while considering port time uncertainty. Aydin et al. (2017) propose a dynamic ship speed optimization model, for determining a liner vessel's optimal sailing speed under fuel cost minimization objectives while considering stochastic port service 
Table 1

A taxonomy of slow steaming-related research.

\begin{tabular}{|c|c|c|c|c|c|}
\hline Authors & S-S & S-S-O & U-P-S-T & V-D-C & S-I-C \\
\hline Tezdogan et al. (2014) & $\mathrm{x}$ & & & $\mathrm{x}$ & \\
\hline Brouer et al. (2013) & $\mathrm{x}$ & & $\mathrm{x}$ & $\mathrm{x}$ & \\
\hline Li et al. (2016) & & $\mathrm{x}$ & $\mathrm{x}$ & $\mathrm{x}$ & $\mathrm{x}$ \\
\hline Fischer et al. (2016) & & $\mathrm{x}$ & $\mathrm{x}$ & $\mathrm{x}$ & \\
\hline Lee et al. (2017) & & $\mathrm{x}$ & $\mathrm{x}$ & $\mathrm{x}$ & \\
\hline Rahman et al. (2015) & $\mathrm{x}$ & & & $\mathrm{x}$ & \\
\hline Corbett et al. (2009) & $\mathrm{x}$ & $\mathrm{x}$ & & $\mathrm{x}$ & \\
\hline Lindstad et al. (2011) & $\mathrm{x}$ & $\mathrm{x}$ & & $\mathrm{x}$ & \\
\hline Fagerholt et al. (2010) & $\mathrm{x}$ & $\mathrm{x}$ & & $\mathrm{x}$ & \\
\hline Cariou and Cheaitou (2012) & $\mathrm{x}$ & $\mathrm{x}$ & & $\mathrm{x}$ & \\
\hline Wang and Meng (2012) & $\mathrm{x}$ & $\mathrm{x}$ & & $\mathrm{x}$ & \\
\hline Chang and Wang (2014) & $\mathrm{x}$ & $\mathrm{x}$ & & $\mathrm{x}$ & \\
\hline Fagerholt et al. (2015) & $\mathrm{x}$ & $\mathrm{x}$ & & $\mathrm{x}$ & \\
\hline Magirou et al. (2015) & $\mathrm{x}$ & $\mathrm{x}$ & & $\mathrm{x}$ & \\
\hline Andersson et al. (2015) & $\mathrm{x}$ & $\mathrm{x}$ & & $\mathrm{x}$ & \\
\hline Wang and $\mathrm{Xu}(2015)$ & $\mathrm{x}$ & $\mathrm{x}$ & & $\mathrm{x}$ & \\
\hline Norlund et al. (2016) & $\mathrm{x}$ & $\mathrm{x}$ & & $\mathrm{x}$ & \\
\hline Adland et al. (2017) & $\mathrm{x}$ & $\mathrm{x}$ & & $\mathrm{x}$ & \\
\hline Wen et al. (2017) & $\mathrm{x}$ & $\mathrm{x}$ & & $\mathrm{x}$ & \\
\hline Guericke and Tierney (2015) & $\mathrm{x}$ & $\mathrm{x}$ & & $\mathrm{x}$ & \\
\hline Lee et al. (2015) & $\mathrm{x}$ & $\mathrm{x}$ & $\mathrm{x}$ & $\mathrm{x}$ & $\mathrm{x}$ \\
\hline Song et al. (2015) & $\mathrm{x}$ & $\mathrm{x}$ & $\mathrm{x}$ & $\mathrm{x}$ & \\
\hline Psaraftis and Kontovas (2010) & $\mathrm{x}$ & $\mathrm{x}$ & & $\mathrm{x}$ & $\mathrm{x}$ \\
\hline Psaraftis and Kontovas $(2013,2014)$ & $\mathrm{x}$ & $\mathrm{x}$ & & $\mathrm{x}$ & $\mathrm{x}$ \\
\hline Maloni et al. (2013) & $\mathrm{x}$ & $\mathrm{x}$ & & $\mathrm{x}$ & $\mathrm{x}$ \\
\hline Harrison and Fichtinger (2013) & $\mathrm{x}$ & $\mathrm{x}$ & & $\mathrm{x}$ & $\mathrm{x}$ \\
\hline
\end{tabular}

times and port delay penalties. Li et al. (2016) propose a dynamic programming model for regular sea voyage and port delay recovery and occasional disruption event recovery that mainly occur at ports, through the adjustment of the vessel's sailing speed. The optimization criteria involve, the vessel's fuel and operating costs per voyage, and the vessel's delay costs which incorporate the cargo's misconnecting, inventory and rerouting costs, along with the shippers goodwill loss cost. Fischer et al. (2016), develop a mixed integer linear programming and a rolling horizon heuristic model for minimizing the voyage costs of a fleet of vessels under alternative ship voyage and port delay recovery strategies. Finally, Lee et al. (2017), proposed a multi-objective, voyage cost and delay minimization model, while considering the impact of the weather on the vessel's voyage fuel consumption and travel times. The optimization criteria involve the vessel's voyage costs and times.

As slow steaming increases the replenishment times of a shipper's order, leading to higher pipeline inventory and safety stock holding costs for the shipper, several researchers focus on the quantification of the cost impact of slow steaming jointly on the carrier and the shipper. On this basis, Psaraftis and Kontovas (2010), and Psaraftis and Kontovas (2013, 2014) provide various ship speed optimization models that minimize the carrier's voyage cost and the shipper's pipeline inventory holding costs under alternative routing scenarios and hinterland modal split options. Maloni et al. (2013) developed a simulation-based ship speed optimization modelling methodology that minimizes the carrier's voyage costs and $\mathrm{CO}_{2}$ emissions and the shipper's pipeline inventory holding costs, while evaluating the impact of slow steaming throughout the whole SC, as future fuel prices and container volumes change. Finally, Harrison and Fichtinger (2013) developed a discrete event simulation model for evaluating the impact of the voyage delays on the shipper's inventory levels under different predefined fill rate constraints.

Table 1 provides a taxonomy of the relevant papers based on the relevant research areas that they tackle, namely slow steaming (S-S), sailing speed optimization (S-S-O), uncertain port service times (U-P-S-T), vessel's deployment costs (V-D-C) and shipper's inventory costs (S-I-C).

The conducted taxonomy clearly indicates that:

i. the majority of the existing research works propose models that solely optimize the vessel's speed;

ii. there is a small number of research papers that determine the optimal vessel's slow steaming speeds, under voyage costs and shipper's inventory cost optimization objectives, and only one research effort that also evaluates the impact of uncertain port times in the slow steaming speed decision-making process. These papers mainly employ simulation methodologies that evaluate the impact of slow steaming speed on the shipper's pipeline, and safety stock holding costs and not on the shipper's total landed logistics costs.

\section{Problem under study}

In this Section, we motivate and describe the problem under study, while we further provide all relevant assumptions. More specifically, we examine a multinational company operating in the European Union, which has developed a typical centralized 
distribution network for supplying its demand points within the EU. In order to do so, the company (also known as the "shipper" or the "cargo owner"), usually leases storage capacities in large centralized distribution centers (CDCs), one at each intermediate port of the liner shipping connections. The shipper further assigns to the CDCs' decision-makers, its inventory management and control tasks. These decision-makers place orders to the company's offshored central manufacturing facilities, usually located in Asia and are being replenished through a combination of deep-sea shipping and inland transportation connections. The shipper's demand points are then replenished by the central DC of each intermediate port through truck or rail or barge.

The carrier owns a number of vessels. Each vessel has a lay day clause with shippers' in the entry ports of his shipping network and employs slow steaming. As under slow steaming the length of the voyage duration increases, and the demand during the increased voyage times is accumulated, the carrier may have to employ additional vessels in order to support its strategically designed delivery frequency.

As by far, the lengthiest part of the shipper's supply chain involves the ship voyage distance from the distant manufacturer to the port of entry, the impact of slow steaming on the shipper's logistics costs is mainly being absorbed by the CDC which has to maintain high inventory levels in order to provide competitive service levels to its serving demand points. We will therefore examine a twoechelon (manufacturer-DC) distribution structure for various fast-moving stock keeping units (SKUs) ordered by the CDC of each intermediate port. These orders are transported in containers through deep-sea shipping from a faraway Loading Port (LP) to a European Entry Port (EP), and then, through inland transportation connections to the CDC.

As the deep-sea shipping lead-time from the LP to the EP is lengthy, the lead-time demand variability that the CDC encounters is high, leading to high safety stock requirements. In order to compensate for the increased variability, each CDC continuously evaluates its inventory positions and sets batch orders to the offshored manufacturing site. Thus, in our analysis, a continuous review (Q, R) inventory planning policy is employed for the replenishment of each CDC's stock from the offshore manufacturer.

The cost impact of the carrier's slow steaming speed on the total logistics costs of the shipper at each intermediate port involves the optimization of: (i) the safety stock level reserved at the CDC; and (ii) the order batch size placed to the distant manufacturing site by each CDC.

The shipper's cost optimization criteria at each intermediate port involve: (i) the CDC's holding costs per SKU per time unit; (ii) the CDC's backorder cost per SKU stockout; (iii) each CDC's operating costs per time unit associated to the storage capacity of the CDC leased by the shipper; and finally, (iv) the pipeline inventory holding costs per SKU from the distant loading point to each CDC.

On the other hand, the impact of slow steaming on the carrier's voyage costs is quantified through the numerical solution of a voyage cost function for each slow steaming speed, which consists of: (i) the vessel's operating costs per day; (ii) the bunker fuel costs per ton of fuel consumed; (iii) the fixed port-related costs per voyage and the variable port-related costs per full container load (FCL) and (iv) the fixed voyage canal costs.

\section{The overall carrier's and shipper's model under speed adjustment}

In this Section, we present the development of the model employed for evaluating the impact of slow steaming on the carrier's voyage costs per full container load (FCL) under a speed adjustment policy. This impact is thoroughly discussed in Section 4.1. and it hinges upon: (i) the increased voyage duration under slow steaming, and (ii) the reduction of voyage time variability, as after a potential voyage delay occurrence, the vessel can increase speed to absorb part of, or all of the delay, if it sails at a higher speed.

Thus, Section 4.1 proposes a new model for evaluating for each slow steaming speed the expected ship voyage duration for the various ports across the route under a speed adjustment policy. These durations are then incorporated as an input into: (i) the methodology presented in Section 4.2 for determining the vessel's slow steaming speeds; (ii) the voyage cost activity-based model presented in Section 4.3 for quantifying the impact of slow steaming on the carrier's voyage costs; and (iii) the continuous review inventory planning model, presented in Section 4.4, for quantifying the impact of slow steaming on the shipper's logistics costs.

\subsection{Expected ship voyage duration}

The shipping line under study consists of a port of origin 1 and a number of intermediate ports of the round trip before returning back to port 1 . The carrier strategically determines the sequence of the ports that the vessel will follow (Meng et al., 2014). The vessel is not allowed to skip intermediate ports (a practice known as "blank shipping"), due to high container volume demands at the intermediate ports that must be served on time as designated by the carrier's layday clauses with the shippers at the intermediate ports. The shipping network realization under study is illustrated in Fig. 1, while the nomenclature is listed in Table 2.

In the shipping network under study, the shipping line determines a nominal voyage speed $S$ for the vessel for all voyage segments from Port 1 and back. However, at the beginning of segment $i$, the vessel encounters an accumulated delay that consist of the delay during the voyage due to adverse weather conditions plus the delay at the port, and speeds up in order to compensate this delay and thus honor the layday clauses with its shippers at the next port. The value of this adjusted speed $S_{i}$ (which is assumed constant along each segment) depends on the magnitude of the delay. More specifically, if the vessel can fully compensate the total delay with a speed adjustment, it will select the necessary adjusted speed that leads its scheduled on-time arrival. Otherwise, the vessel will travel at its maximum speed $S_{m}$ in order to cover as much of the delay possible. In this case, the delay that the vessel will realize in the beginning of the next voyage segment (effective delay $r_{i}^{\prime}$ ), will be the remaining delay from the previous segment plus any delay $r_{i}$ that will occur in the port between these segments. We assume that there is no remaining delay at port 1 (i.e. $r_{1}^{\prime}=r_{1}$ ).

The effective delay $r_{i}^{\prime}$ is given by: 


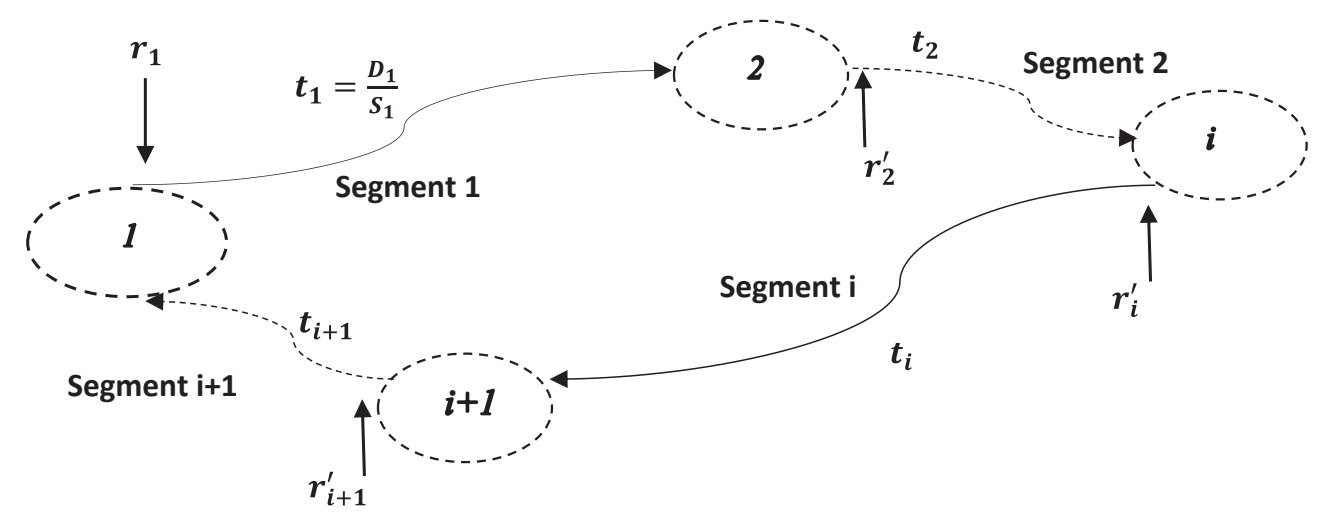

Fig. 1. Shipping network realization.

Table 2

Nomenclature.

\begin{tabular}{ll}
\hline Parameters & Description \\
\hline$S$ & Nominal slow steaming speed of the vessel \\
$S_{i}$ & Vessel's adjusted speed at segment $i$ \\
$D_{i}$ & Distance of segment $i$ \\
$t_{i}$ & Time required for covering segment $i$ \\
$r_{i}$ & Realization of a random delay $r_{i}$ at port $i$, with probability density function $f_{R_{i}}\left(r_{i}\right)$ and cumulative distribution function $F_{R_{i}}\left(r_{i}\right)$ \\
$r_{i}^{\prime}$ & Effective delay that is realized at the beginning of segment $i$ \\
\hline
\end{tabular}

$$
r_{i}^{\prime}=r_{i-1}^{\prime}+r_{i}-\left(\frac{\mathrm{D}_{\mathrm{i}-1}}{\mathrm{~S}}-\frac{\mathrm{D}_{\mathrm{i}-1}}{\mathrm{~S}_{\mathrm{i}-1}}\right)
$$

and the adjusted speed of $S_{i}$ is given by:

$$
S_{i}=\mid \begin{array}{ll}
S_{m} & \text { if } r_{i}^{\prime}>\Delta_{i}=\frac{D_{i}}{S}-\frac{D_{i}}{S_{m}} \\
\frac{D_{i} S}{D_{i}-S r_{i}^{\prime}} & \text { if } r_{i}^{\prime} \leqslant \Delta_{i}=\frac{D_{i}}{S}-\frac{D_{i}}{S_{m}}
\end{array} .
$$

Given the above two cases of the adjusted speed $S_{i}$, and as the voyage duration at each segment $i$ is defined as the segment's port delay plus the actual travel time, the voyage duration at each segment is then provided by:

$$
T_{i}^{S}=\mid \begin{array}{ll}
\frac{D_{i}}{S_{m}}+r_{i} \quad \text { if } r_{i}^{\prime}>\Delta_{i} \\
\frac{D_{i}}{\frac{D_{i} S}{D_{i}-S r_{i}^{\prime}}}+r_{i} & \text { if } r_{i}^{\prime} \leqslant \Delta_{i}
\end{array} .
$$

In the first case, delay $r_{i}^{\prime}$ cannot be compensated $\left(r_{i}^{\prime}>\Delta_{i}\right)$ under speed adjustment. In this case, the vessel will travel under max speed $S_{m}$ to cover as much of the delay $r_{i}^{\prime}$ as possible. In the second case, delay $r_{i}^{\prime}$ can be compensated $\left(r_{i}^{\prime} \leqslant \Delta_{i}\right)$ through speed adjustment, and thus, the vessel will travel under its adjusted speed $S_{i}=\frac{D_{i} S}{D_{i}-S r_{i}^{\prime}}$.

Thus, the expected voyage duration of each segment $i$ can be determined analytically through Eq. (1). The integration includes all previous segments since the effective delay $r_{i}^{\prime}$ may be dependent on the stochastic delays at previous segments.

$$
E\left(T_{i}^{S}\right)=\int_{r_{1}=0}^{\infty} \int_{r_{2}=0}^{\infty} \cdots \int_{r_{i=0}}^{\infty} T_{i}^{S} f_{R_{i}}\left(r_{i}\right) \cdots f_{R_{2}}\left(r_{2}\right) f_{R_{1}}\left(r_{1}\right) d r_{i} \cdots d r_{2} d r_{1}
$$

Since each random delay is defined with a piecewise function with 2 subdomains, the expected voyage duration of segment $i$ would have $2^{i}$ terms due to all possible combinations of the 2 subdomains of delays $r_{1}, r_{2}, \ldots, r_{i}$.

Specifically, the expected voyage duration for segment 1 has the $2^{1}$ terms of Table 3.

Based on the above cases, the expected value and variance of the voyage duration of Segment 1 can then be calculated from:

$$
\begin{aligned}
& E\left(T_{1}^{S}\right)=\int_{0}^{\Delta_{1}}\left(\frac{D_{1}}{S_{1}}+r_{1}\right) \cdot f_{R_{1}}\left(r_{1}\right) d r_{1}+\int_{\Delta_{1}}^{\infty}\left(\frac{D_{1}}{S_{m}}+r_{1}\right) \cdot f_{R_{1}}\left(r_{1}\right) d r_{1} \\
& \operatorname{Var}\left(T_{1}^{S}\right)=E\left(\left(T_{1}^{S}\right)^{2}\right)-\left(E\left(T_{1}^{S}\right)\right)^{2}
\end{aligned}
$$

For Segment 2, the expected voyage duration has the $2^{2}$ terms of Table 4. 
Table 3

Expected voyage duration cases for Segment 1.

\begin{tabular}{ll}
\hline Cases & $\begin{array}{l}\text { Expected voyage duration (Days) } \\
E\left({ }^{c} T_{1}^{S}\right)\end{array}$ \\
\hline$r_{1}^{\prime}=r_{1}>\Delta_{1}$ & $\int_{\Delta_{1}}^{\infty}\left(\frac{D_{1}}{S_{m}}+r_{1}\right) f_{R_{1}}\left(r_{1}\right) d r_{1}$ \\
$r_{1}^{\prime}=r_{1} \leqslant \Delta_{1}$ & $\int_{0}^{\Delta_{1}}\left(\frac{D_{1}}{S_{1}}+r_{1}\right) f_{R_{1}}\left(r_{1}\right) d r_{1}$ \\
\hline
\end{tabular}

Table 4

Expected voyage duration cases for Segment 2.

\begin{tabular}{ll}
\hline Cases & Expected voyage duration (Days) \\
& $E\left({ }^{c} T_{2}^{S}\right)$ \\
\hline$r_{1} \leqslant \Delta_{1}, r_{2}^{\prime} \leqslant \Delta_{2}$, & $\int_{0}^{\Delta_{1}} \int_{0}^{\Delta_{2}}\left(\frac{D_{2}}{S_{2}}+r_{2}\right) \cdot f_{R_{2}}\left(r_{2}\right) d r_{2} f_{R_{1}}\left(r_{1}\right) d r_{1}$ \\
$r_{1}>\Delta_{1}, r_{2}^{\prime} \leqslant \Delta_{2}$ & $\int_{\Delta_{1}}^{\Delta_{1}+\Delta_{2}} \int_{0}^{\Delta_{1}+\Delta_{2}-r_{1}}\left(\frac{D_{2}}{S_{2}}+r_{2}\right) \cdot f_{R_{2}}\left(r_{2}\right) d r_{2} f_{R_{1}}\left(r_{1}\right) d r_{1}$ \\
$r_{1} \leqslant \Delta_{1}, r_{2}^{\prime}>\Delta_{2}$ & $\int_{0}^{\Delta_{1}} \int_{\Delta_{2}}^{\infty}\left(\frac{D_{2}}{S_{m}}+r_{2}\right) \cdot f_{R_{2}}\left(r_{2}\right) d r_{2} f_{R_{1}}\left(r_{1}\right) d r_{1}$ \\
$r_{1}>\Delta_{1}, r_{2}^{\prime}>\Delta_{2}$ & $\int_{\Delta_{1}}^{\infty} \int_{\Delta_{1}+\Delta_{2}-r_{1}}^{\infty}\left(\frac{D_{2}}{S_{m}}+r_{2}\right) \cdot f_{R_{2}}\left(r_{2}\right) d r_{2} f_{R_{1}}\left(r_{1}\right) d r_{1}$ \\
\hline
\end{tabular}

Thus, based on the above cases, the expected value $E\left(T_{2}^{S}\right)$ and variance $\operatorname{Var}\left(T_{2}^{S}\right)$ of the voyage duration of Segment 2 can be estimated by:

$$
\begin{aligned}
& E\left(T_{2}^{S}\right)=\sum_{c=1}^{4} E\left({ }^{c} T_{2}^{S}\right) \\
& \operatorname{Var}\left(T_{2}^{S}\right)=E\left(\left(T_{2}^{S}\right)^{2}\right)-\left(E\left(T_{2}^{S}\right)\right)^{2}
\end{aligned}
$$

Considering Eqs. (2), (4) and (3) and (5), the expected value of the voyage duration until the second until Port 2 is given by $E\left(T_{1}^{S}\right)+E\left(T_{2}^{S}\right)$, while the variance of the voyage duration by $\operatorname{Var}\left(T_{1}^{S}\right)+\operatorname{Var}\left(T_{2}^{S}\right)$.

Similarly, for Segments 3 and 4, we consider $2^{3}=8$ and $2^{4}=16$ cases respectively, as these are summarized in Tables 20 and 21 of Appendix C. The model could be extended for more than four ports, thus further increasing the complexity of the solution process. However, this seems to be unnecessary since the existing globalized shipping networks usually consist of ports that are partitioned in subsets, where the ports within each subset are closely located to each other. See for example Maersk's AE10 Westbound Network of Fig. 2. Based on this Figure we observe that the network's port subsets are two; namely the westbound subset, which incorporates the

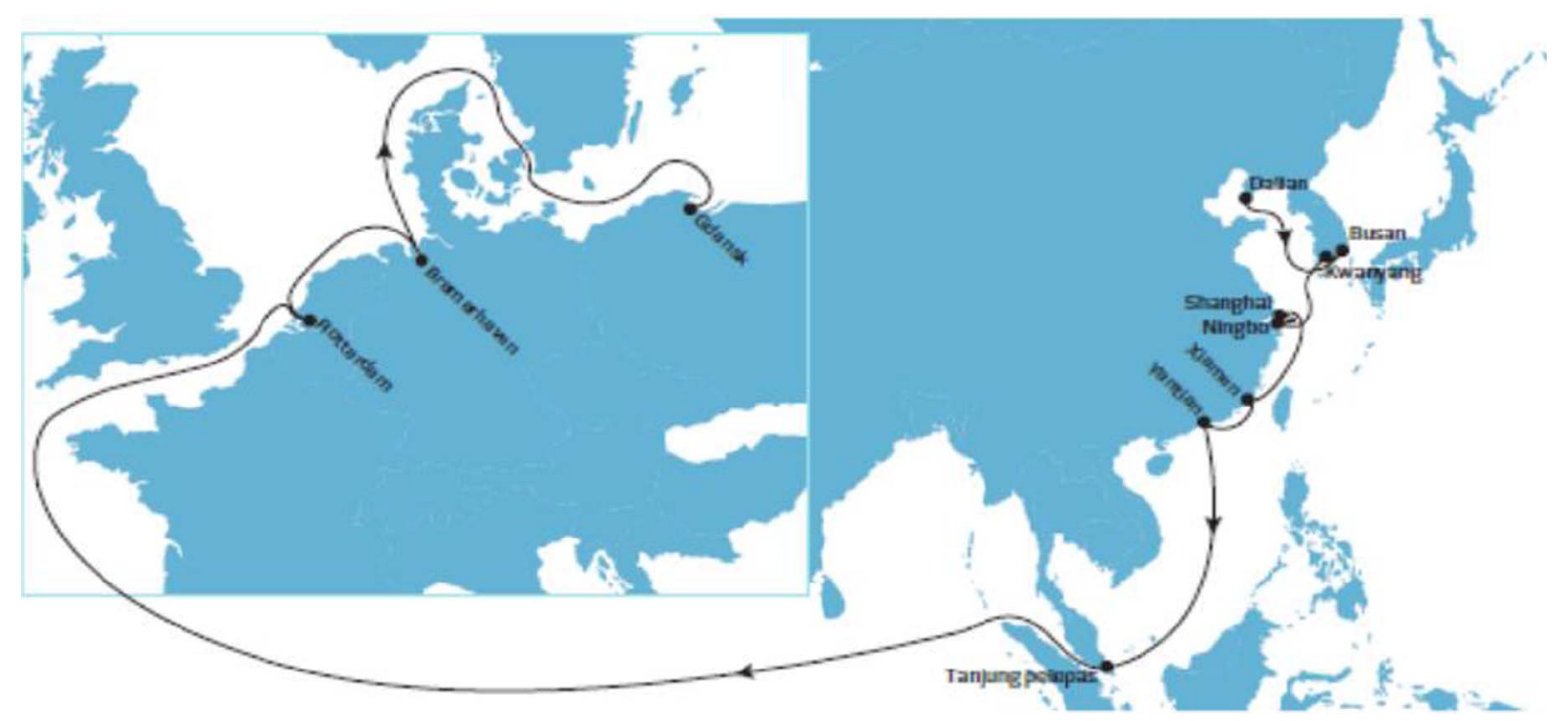

Fig. 2. Maersk's AE10 Westbound Network. Source: Maersk, 2017. 
ports of Dalian, Busan, Kwangyang, Ningbo, Shanghai, Xiamen and Yantian, and the eastbound subset, which incorporates the ports of Rotterdam, Bremenhaven and Gdansk. As these ports are closely located, the impact of speed adjustments on the compensation of their realized delays will be rather insignificant. We can therefore bundle the ports of each subset into one major subset port, assuming that the vessel travels at the same speed within the bundled port cluster, and thus, avoid the unnecessary mathematical complexity stemming from the modelling of the delays of all the intermediate ports. The major subset port will be the subset's last port of call, which further accumulates the port cluster's distances and realized delays. This is a reasonable approximation, which allows for the analytical evaluation of the impact of speed adjustments on the recovery of voyage delays in shipping networks with multiple closely located intermediate ports, while leading to insignificant increases in voyage times and shipper's total landed logistics costs.

\subsection{Selection of slow steaming speeds}

Before proceeding to the vessel's voyage cost estimation under various slow steaming speeds, we need to make the following assumptions: (i) the carrier has a number of identically sized vessels, (ii) the carrier's transportation demand exhibits small variations, and (iii) the capacity utilization of the vessels (namely the average number of containers transported divided by the nominal capacity of the vessel) is the same for all alternative slow steaming speeds. While the first two assumption are necessary to calculate the expected voyage costs per container for a stationary demand, we need the third assumption to ensure that the results for the various slow steaming speeds are comparable.

The proposed rule for selecting the effective slow steaming speeds is explained through the following simple example. If the total voyage duration of a specific line is 49 days at $22 \mathrm{knots}$, in order to maintain a weekly service, the carrier would need at least 7 vessels since $(49$ days $) /(7$ vessels $)=(7$ days per vessel $)$. If the carrier aims to decrease the speed, the carrier should employ an extra vessel ( 8 in total) and thus, the voyage duration could be extended to 56 days $=(8$ vessels $) \times(7$ days per vessel $)$. The slow steaming speed that corresponds to this voyage duration is easily calculated through $(22$ knots $) *(49$ days $) /(56$ days $)=19.2$ knots. Any other speed higher than 19.2 knots would lead to higher vessel fuel consumption and thus costs, without improving the service provided by the line. Thus, we only examine vessel speeds calculated by the above rule.

\subsection{Shipper's costs}

For each shipper at the port of Segment $i$, we examine a two-echelon logistics network for supplying CDC $_{i}$ with a single product type from a distant manufacturing site. As the purpose of this paper is to provide a general solution methodology that can capture the impact of slow steaming on the shipper's logistics costs for the cases of products with different value to volume ratios, i.e. books or laptops vs. white goods, we express the product's demand parameters in full container loads (FCL). We further assume that the demand of the product per time period at $\mathrm{CDC}_{\mathrm{i}}$ in FCLs, denoted by $X_{i}$, is an i.i.d. normal random variable with mean $\mu_{i}$ and standard deviation $\sigma_{i} . C D C_{i}$ employs a continuous review $(\mathrm{Q}, \mathrm{R})$ inventory planning policy aiming to optimize the total landed logistics costs of the shipper. These costs encompass: (i) the on-hand inventory holding costs per FCL per time unit at the $\mathrm{CDC}_{\mathrm{i}}$, $h$; (ii) the backorder costs per FCL stockout at $\mathrm{CDC}_{\mathrm{i}}, b$; (iii) the facility operating costs per time unit, $C_{K_{C D C i}}$; and (iv) its pipeline inventory holding cost per FCL per time unit from the distant loading point, $h^{p}$.

The lead time of $\mathrm{CDC}_{\mathrm{i}} L_{S}^{i}$, is stochastic as it consists of the stochastic voyage duration till the destination port of segment $i$, the delay until and the dwell time at the port of segment $i$, plus the transportation time from the destination port of segment $i$ to CDC $_{\mathrm{i}}$. Thus, the examined product's mean and standard deviation of demand during $L_{S}^{i}$ time units are provided by the following well-known equations (Chopra and Meindl, 2004, pp. 311):

$$
\begin{aligned}
& \mu_{L_{S}^{i}}=\mu_{i} \cdot E\left(L_{S}^{i}\right), \\
& \sigma_{L_{S}^{i}}=\sqrt{E\left(L_{S}^{i}\right) \cdot \sigma_{i}^{2}+\mu_{i}^{2} \cdot S_{L_{S}^{i}}^{2}} .
\end{aligned}
$$

For each slow steaming speed, the product's expected on-hand inventory level and its expected number of backorders per replenishment cycle for standard normal demand are then provided by Eqs. (8) and (9), respectively (Silver et al., 1998):

$$
\begin{aligned}
& E\left(I L_{S}^{i}\right) \simeq \sigma_{L_{S}^{i} \cdot z_{S}^{i}}+\frac{Q_{S}^{i}}{2} \\
& E\left(B O_{S}^{i}\right)=\sigma_{L_{S}^{i}} \cdot\left[\varphi\left(z_{S}^{i}\right)-z_{S}^{i}\left(1-\Phi\left(z_{S}^{i}\right)\right)\right],
\end{aligned}
$$

where:

- $Q_{S}^{i}$ is a decision variable which represents the order batch size set by the inventory planner of the CDC at the distant manufacturer;

- $z_{S}^{i}$ is a decision variable representing the safety stock factor of the examined product at the CDC;

- $\Phi\left(z_{S}^{i}\right)$ represents the cumulative distribution function of the product's standardized normal demand per time unit at the CDC;

- $\varphi\left(z_{S}^{i}\right)=d \Phi\left(z_{S}^{i}\right) / d z_{S}^{i}$ is the probability density function of the product's standardized normal demand in FCLs per time unit;

- $\sigma_{L_{S}^{i}}$ represents the standard deviation of demand in FCLs during $L_{S}^{i}$ time units;

- $S_{L_{S}^{i}}^{2}$ represents the variance of the lead time $L_{S}^{i}$. 
Table 5

Decision variables.

$\begin{array}{ll}z_{S}^{i} & \text { Safety stock factor of the examined product at the } C D C_{i}, \text { for each slow steaming speed. } \\ Q_{S}^{i} & \text { Order batch quantity for the examined product in FCLs, for each slow steaming speed (FCLs). }\end{array}$

In order to estimate the CDC's operating cost per time unit associated to the CDC capacity $\left(K_{S}^{i}\right)$ leased by the shipper for the storage of the product type examined, we employ the methodology proposed by Mallidis et al. (2014). We thus employ: $K_{S}^{i}=\sigma_{L_{S}^{i}} \cdot z_{S}^{i}+Q_{S}^{i}$, consisting of: (i) a safety stock $\sigma_{L_{S}^{i}} z_{S}^{i}$; and (ii) a capacity $Q_{S}^{i}$ which is assumed large enough to handle its average peak demand during its stochastic lead time $L_{S}^{i}$. This capacity is then expressed as a ratio to the CDC's total capacity $\left(K_{C D C_{i}}\right)$ which is considered preset. The ratio of the product's leased storage capacity to the preset capacity of the CDC, is then multiplied by the CDC's total operating costs which are also fixed as they are estimated as a non-linear function of its preset capacity $\left(\mathrm{K}_{C D C_{i}}\right)$.

\subsubsection{Cost optimization model}

We employ a cost objective function that minimizes the shipper's inventory-related costs at the CDC. Tables 5 and 6 provide the nomenclature of the model's decision variables and cost parameters, respectively.

The holding cost per FCL per time unit, $h$, is charged on the expected on-hand inventory level at the $\mathrm{CDC}_{\mathrm{i}}$, while the pipeline inventory holding cost per FCL per time unit, $h^{p}$, is charged on the product's mean lead time demand $\left(\mu_{L_{S}^{i}}\right)$ from the Loading Point to $\mathrm{CDC}_{\mathrm{i}}$. The backorder cost per FCL stockout, b, is charged on the expected number of stockouts per time unit, $\left(\mu_{i} / Q_{S}^{i}\right) \cdot E\left(B O_{S}^{i}\right)$ where $E\left(B O_{S}^{i}\right)$, represents the expected number of backorders per replenishment cycle. The transportation cost per FCL trip $C_{D}$ is charged on the mean demand in FCLs per time unit $\mu_{i}$. Finally, the $\mathrm{CDC}_{i}$ 's operational costs assigned to the shipper's leased storage capacity are equal to the ratio of the product's leased capacity $K_{S}^{i}$, to the $\mathrm{CDC}_{\mathrm{i}}$ 's preset capacity $\mathrm{K}_{C D C_{i}}$, multiplied by the $\mathrm{CDC}_{\mathrm{i}}$ 's nonlinear total operating costs per time unit, $C_{\mathrm{K}_{C D C}},\left(K_{S}^{i} / \mathrm{K}_{C D C_{i}}\right) \cdot C_{\mathrm{K}_{C D C_{i}}}$.

Consequently, the shipper's expected total cost per time unit $E\left(T C_{S}^{i}\right)$ is minimized with respect to the safety stock factor $z_{S}^{i}$ (expressions $E\left(I L_{S}^{i}\right), E\left(B O_{S}^{i}\right)$ ), and $K_{S}^{i}$ ), and the order batch quantity $Q_{S}^{i}$ (expressions $E\left(I L_{S}^{i}\right), K_{S}^{i}, \mu_{i} / Q_{S}^{i}$ ) through:

$$
\min E\left(T C\left(Q_{S}^{i}, z_{S}^{i}\right)=\mathrm{h} \cdot E\left(I L_{S}^{i}\right)+b \cdot\left(\mu_{i} / Q_{S}^{i}\right) \cdot E\left(B O_{S}^{i}\right)+C_{D_{i}} \cdot \mu_{i}+h^{p} \cdot \mu_{L_{S}^{i}}+\left(K_{S}^{i} / \mathrm{K}_{C D C_{i}}\right) \cdot C_{\mathrm{K}_{C D C_{i}}}\right.
$$

The shipper's expected total cost per FCL can be then easily derived by multiplying Eq. (10), with $1 / \mu_{i}$. The optimization of Eq. (10) with respect to the safety stock factor $z_{S}^{i}$ and order batch size $Q_{S}^{i}$ leads to the following Proposition I.

Proposition I. The cost objective function is convex, and the optimal value of the examined product's safety stock factor $z_{s}^{i}$ and the order batch quantity $Q_{s}^{i}$ at the CDC are jointly obtained from:

$$
\begin{aligned}
& \Phi\left(z_{S}^{i}\right)=\left[b \cdot \mu_{i} \cdot \mathrm{K}_{C D C_{i}}-\mathrm{C}_{C D C_{i}} \cdot Q_{S}^{i}-h \cdot Q_{S}^{i} \cdot \mathrm{K}_{C D C_{i}}\right] / b \cdot \mu_{i} \cdot \mathrm{K}_{C D C_{i}}, \\
& Q_{S}^{i}=\sqrt{\left[b \cdot \mu_{i} \cdot \sigma_{L_{S}^{i}} \cdot\left(\varphi\left(z_{S}^{i}\right)-z_{S}^{i} \cdot\left(1-\Phi\left(z_{S}^{i}\right)\right)\right)\right] /\left[\frac{h}{2}+\frac{\mathrm{C}_{C D C_{i}}}{\mathrm{~K}_{C D C_{i}}}\right]},
\end{aligned}
$$

only for values of $z_{S}^{i} \geqslant 0.5531$ (for the Proof see Appendix A).

A close observation of Eq. (11) indicates that the impact of slow steaming, through the higher lead times $\left(L_{S}^{i}\right)$, on the optimal safety stock factor $z_{S}^{i}$ is indirect as it depends on $Q_{S}^{i}$, while Eq. (12) indicates that the marginal impact of lower ship speeds on the CDC's order batch quantity $Q_{S}^{i}$, continuously decreases as the lead time $L_{S}$ increases according to the root of the standard deviation of demand during the stochastic lead time $L_{S}^{i}\left(\sqrt{\sigma_{L_{S}^{i}}}\right)$.

\subsection{An activity-based voyage cost estimation model}

The employment of slow steaming may lead to lower fuel consumption, which in turn leads to lower fuel costs, and lengthier voyage times, which lead to higher operational costs. To capture these impacts, we estimate the carrier's voyage costs of each segment, assuming that the shipping line has a fleet of same sized carriers, and employ a shipping cost model similar to that of Brouer

Table 6

Parameters.

\begin{tabular}{ll}
\hline$h$ & Holding cost per time unit per FCL $(€ /$ time unit/FCL) \\
$h^{p}$ & Pipeline inventory holding cost per time unit per FCL $(€ /$ time unit/FCL) \\
$b$ & Backorder cost per FCL stockout at the $\mathrm{CDC}_{\mathrm{i}}(€ / \mathrm{FCL})$ \\
$C_{D_{i}}$ & Transportation cost per FCL from the entry port to the $\mathrm{CDC}_{\mathrm{i}}(€ / \mathrm{FCL})$ \\
$K_{S}^{i}$ & Product's leased storage capacity at the CDC $=\sigma_{L_{S}^{i}} \cdot z_{S_{1}}+Q_{S_{1}}(\mathrm{FCLs})$ \\
$K_{C D C_{i}}$ & Preset capacity of the examined $\mathrm{CDC}_{\mathrm{i}}(\mathrm{FCLs})$ \\
$C_{K_{C D C_{i}}}$ & Nonlinear total operational cost of the $\mathrm{CDC}_{\mathrm{i}}$ per time unit $(€ /$ time unit)
\end{tabular}


Table 7

Parameters of the activity-based voyage cost evaluation model.

\begin{tabular}{ll}
\hline Parameters & Description \\
\hline$C_{O}$ & Operational costs of the examined vessel (€/day) \\
$F C$ & Bunker fuel cost $(€ /$ ton of fuel) \\
$F_{d}$ & Vessel's voyage fuel consumption at its design speed (tons/day) \\
$F$ & Vessel's fuel consumption when idle (tons of fuel/day). \\
$S_{d}$ & Vessel's design (d) speed (knots/hour) \\
$P C_{F_{i}}$ & Fixed port-related costs of segment $i(€ /$ segment voyage). \\
$P C_{\text {var }}$ & Variable port-related cost of segment $i(€ / \mathrm{FCL} /$ segment voyage) \\
${ }^{i} C_{\text {canal }}$ & Voyage canal costs (€/segment voyage) \\
$t_{\mathrm{dwell}}^{i}$ & Ship dwell time at the port of segment $i$ (days/segment voyage) \\
$N_{i}$ & Vessel's Average Carrying Capacity in each Segment of the Voyage (FCLs) \\
\hline
\end{tabular}

et al. (2014). The nomenclature of the employed model is summarized in Table 7.

The voyage cost of each segment $i$ then consists of the vessel's sailing costs, ${ }^{i} C_{S}^{S a i l}=\left(T_{i}^{S}\right) \cdot\left[C_{0}+V F C_{i}\right]$, where $V F C_{i}=\left[F C \cdot\left(\frac{S_{i}}{S_{d}}\right)^{3} \cdot F_{d}\right]$ represents the vessel's fuel costs per day, and $S_{i} / S_{d}$ represents the ratio of the vessel's adjusted voyage speed to the vessel's design speed $\left(S_{d}\right)$, the vessel's canal costs per voyage ${ }^{i} C_{\text {canal }}$ assigned to each Segment $i$ of the voyage equally, the vessel's fixed port related cost of segment $i P_{F}^{i}=\left[F C \cdot F \cdot t_{\mathrm{dwell}}^{i}+P C_{F_{i}}\right]$ and the vessel's variable origin-port related costs per container at each segment $\mathrm{i}, P C_{V^{2} r_{i}}^{i}$. Given the above parameters, and considering the different cases and associated adjusted speeds $S_{i}$ for estimating the expected voyage duration of Segment $i$, the voyage costs of Segment $i$ per FCL in the inbound (forward) and outbound (return) part of the round trip, are provided by Eq. (13).

$$
E\left(V C_{S}^{i}\right)=\left(\frac{E\left(C_{S}^{S a i l}\right)+P_{F}^{i}+{ }^{i} \text { Ccanal }}{N_{i}}\right)+P C_{\text {Var }_{i}}^{i}
$$

\section{The case study of a global logistics network}

We illustrate the applicability of the proposed methodology on a realistic shipping network of an Asian white goods manufacturer, who supplies the EU market through the entry Ports of Algeciras and Rotterdam, and a European machinery manufacturer who supplies the Asian Market through the Ports of Muscat in Oman and Shanghai. More specifically, the Asian manufacturer supplies the markets of Spain, and Portugal through the Port of Algeciras and the market of Germany through the Port of Rotterdam. The European exporter supplies the markets of Oman, Bahrain and Dubai through the Port of Muscat, while the market of China, through the Port of Shanghai. With respect to the Asian white goods manufacturer, we examine the supply of one of its goods, namely refrigerators, while for the European machinery exporter, and as we do not have any demand data for Oman, Bahrain, Dubai and Shanghai, we consider a typical machinery that exhibits the similar size and demand variability as that of refrigerators, and determine the demand of each country as a ratio of its GDP to the GDP of Germany.

Both the refrigerators and the machinery are exported in $40 \mathrm{ft}$ Equivalent Units (FEUs), thus in the case study FCL $=$ FEU. The FEUs are transported with a 15,000 TEU (or 7500 FEUs) mother vessel to the examined ports, and then through truck transportation to the premises of $100,000 \mathrm{~m}^{3} \mathrm{CDCs}$ established in the ports' nearest cities Considering an average refrigerator sales value of $453 €$ (Miche et al., 2015) and by deducting a 21\% VAT value and a 50\% total profit rate of the manufacturer and the final retailer (total $71 \%$ ), the refrigerator's net average value is estimated as $453 € / 1.71=265 € /$ refrigerator, leading to an average value per FEU equal to $10,547 €(265 € /$ refrigerator x 39.8 refrigerators/FEU), as one FEU typically carries 39.8 refrigerators. We assume the same values for the machinery FEU.

\subsection{Estimation of voyage delays}

In order to determine the voyage delays in the route from Shanghai to Rotterdam and back to Shanghai, and as the stochastic delay data of the container terminals of Algeciras, Rotterdam, Muscat and Shanghai are not available, we employed a heuristic methodology, based on which, we estimate the total voyage delay from Shanghai to Rotterdam and Rotterdam Shanghai based on real delay data in these routes, and then, allocate these delays at the ports along the routes. The steps considered for the allocation process are summarized below.

\section{Step 1: Determination of the Total Voyage Delay}

In this step, we determine the total voyage delay from Shanghai to Rotterdam, employing the containership delay data, retrieved by the Drewry Shipping Consultants' Report of 2014 (see Table 22 of Appendix D). These data include delay data from a sample of 2919 vessels in all routes. In order to determine the distribution of ship voyage delays, we tested several distributions with a Chisquare test. The CDF, the obtained $\mathrm{x}_{0}^{2}$ values, and the distribution parameter values for each one of the examined distribution 
functions are summarized in Table 23 of Appendix D. Given the threshold value of $x_{10,0.99}^{2}=23.2$, the Gamma distribution is not rejected as in this case, $x_{0}^{2}<x_{10,0.99}^{2}$. Thus, and considering the Gamma Distribution with parameters $\kappa_{\gamma}=0.42$ and $\theta_{\gamma}=3.4$, the obtained mean and variance of the stochastic voyage delay is therefore $\kappa_{\gamma} . \theta_{\gamma}=1.42$ and $\kappa_{\gamma} .\left(\theta_{\gamma}\right)^{2}=4.81$ days ${ }^{2}$.

Step 2: Allocation of the total Voyage Delays to the Container Terminals of Algeciras and Rotterdam in the westbound network and of Oman, Shanghai in the eastbound network.

The criterion for allocating the total voyage delays of Step 1 is the average ship dwell time at these ports. These times are summarized in Table 24 of Appendix D. Assuming that the delays at each one of the container terminals also follow the Gamma Distribution, and considering the percentages of Table 24, the mean and variance of the delay at each container terminal are listed in Table 25.

Step 3: Determination of the $\kappa_{\gamma}, \theta_{\gamma}$ parameters of the Gamma distribution at the examined container terminals.

The final step of our analysis, is to determine the $\kappa_{\gamma}, \theta_{\gamma}$ parameters of the Gamma Distributed delays at the examined container terminals, given the mean and variance of the Delays of Table 25. Then, and considering the CDF functions of Table 23, we obtain the $\kappa_{\gamma}$ and $\theta_{\gamma}$ parameters of the Gamma distribution for each port as these are summarized in Table 27.

\subsection{Estimation of efficient slow steaming speeds}

The last generation container ships have typically a maximal speed of 22 knots. While these ships can sail at speeds as low as 14 or even 12 knots in some cases (Rodrigue, 2017), below this speed it becomes difficult to control the vessel. Accordingly, we will consider the slow steaming speed range of 14-22 knots. Given the rule proposed in Section 4.2, and considering an estimated roundtrip voyage duration at 22 knots equal to 48 days, the carrier requires 7 vessels for honoring its weekly delivery, leading to a voyage time of 7 weeks per vessel. Thus, the slow steaming speeds that the carrier must adopt in order to effectively utilize the additional idle vessels employed, are summarized in Table 8.

\subsection{Voyage duration}

Considering the effective slow steaming speeds of Table 8, the expected values and variances of the respective to the speeds, voyage durations are displayed in Table 9.

\subsection{Estimation of shipper's demand in FEUs}

The shipper's average daily demand in Algeciras is 275 refrigerators while in Rotterdam, 1,131 refrigerators. These figures where determined based on historical demand data of in the EU, provided by the Euromonitor International (2016), with an additional assumption that the company captures a market share of $10 \%$ for imported refrigerators.

For the shipper in Oman, the demand of the transported machinery is estimated as $(0.186$ trillion $€ / 3.3$ trillion $€) \cdot 1,131=64$ machinery items per day, where ( 0.186 trillion $€ / 3.3$ trillion $€$ ), represents the ratio of the sum of the GDPs of Oman Bahrain and United Arabic Emirates to that of Germany. Similarly, for Shanghai demand is 3616 units. Considering an average number of 39.8 refrigerators per FEU, and assuming the same number of machinery items per FEU, the mean daily demand considered of the Shipper in Algeciras is $6.9 \mathrm{FEUs/day,} \mathrm{of} \mathrm{Rotterdam} \mathrm{is} 28.4 \mathrm{FEUs} /$ day, of Oman is 2 FEUs/day, and of Shanghai 90.8 FEUs/day. As daily variations of demand were not available, we considered a steady normally distributed daily demand with a coefficient of variation $\mathrm{CV}=0.8$, leading to a standard deviation of daily demand equal to 5.5 FEUs for the shipper of Algeciras, 22.7 FEUs for the shipper in Rotterdam, 1.6 FEUs for the shipper of Oman and 73 FEUs for the shipper in Shanghai.

Tables 10-13 display the mean lead time demand $\left(\mu_{L_{S}^{i}}\right)$, as estimated by Eq. (6), the standard deviation of lead time demand $\left(\sigma_{L_{S}^{i}}\right)$ estimated by Eq. (7), and the coefficient of variation of lead time demand $\left(\sigma_{L_{S}^{i}} / \mu_{L_{S}^{i}}\right)$ for all 4 segments.

An interesting finding obtained from Tables $10-13$ is that even though the mean and the standard deviation of the lead time demand increases, its CV is reduced due to the reduced voyage time variability that is achieved realized under slow steaming.

Table 8

Effective slow steaming speeds for a weekly delivery schedule.

\begin{tabular}{ll}
\hline Number of vessels & Effective speeds (knots) \\
\hline 7 & 22 \\
8 & $22 \cdot(7 / 8)=19.3$ \\
9 & $22 \cdot(7 / 9)=17.1$ \\
10 & $22 \cdot(7 / 10)=15.4$ \\
11 & $22 \cdot(7 / 11)=14.0$ \\
\hline
\end{tabular}


Table 9

Vessel's expected value and variance of the voyage duration per Segment.

\begin{tabular}{|c|c|c|c|c|c|c|c|c|}
\hline \multirow{2}{*}{$\begin{array}{l}\text { Speed } \\
\text { knots }\end{array}$} & \multicolumn{2}{|c|}{ Segment 1 (days)-(days) ${ }^{2}$} & \multicolumn{2}{|c|}{ Segment 2(days)-(days) ${ }^{2}$} & \multicolumn{2}{|c|}{ Segment 3(days)-(days) ${ }^{2}$} & \multicolumn{2}{|c|}{ Segment 4(days)-(days) ${ }^{2}$} \\
\hline & $E\left(T_{1}^{S}\right)$ & $\operatorname{Var}\left(T_{1}^{S}\right)$ & $E\left(T_{2}^{S}\right)$ & $\operatorname{Var}\left(T_{2}^{S}\right)$ & $E\left(T_{3}^{S}\right)$ & $\operatorname{Var}\left(T_{3}^{S}\right)$ & $E\left(T_{4}^{S}\right)$ & $\operatorname{Var}\left(T_{4}^{S}\right)$ \\
\hline 22.0 & 17.88 & 2.07 & 3.12 & 1.89 & 12.07 & 3.05 & 10.86 & 2.80 \\
\hline 19.3 & 19.85 & 0.85 & 3.27 & 1.86 & 12.89 & 2.72 & 11.52 & 2.23 \\
\hline 17.1 & 22.27 & 0.33 & 3.57 & 1.66 & 14.35 & 1.66 & 12.94 & 1.85 \\
\hline 15.4 & 24.69 & 0.14 & 3.89 & 1.48 & 15.97 & 1.27 & 14.45 & 1.07 \\
\hline 14.0 & 27.14 & 0.06 & 4.22 & 1.31 & 17.44 & 1.05 & 15.79 & 0.70 \\
\hline
\end{tabular}

Table 10

Mean, standard deviation and CV of lead time demand of Segment 1 (Shanghai-Algeciras).

\begin{tabular}{llcr}
\hline Speed (knots) & $\mu_{L_{S}^{i}}($ FEUs) & $\sigma_{L_{S}^{i}}($ FEUs $)$ & $C V$ \\
\hline 22.0 & 132.2 & 26.1 & $19.8 \%$ \\
19.3 & 145.8 & 26.2 & $17.9 \%$ \\
17.1 & 162.5 & 27.1 & $16.7 \%$ \\
15.4 & 179.2 & 28.3 & $15.8 \%$ \\
14.0 & 196.1 & 29.5 & $15.0 \%$ \\
\hline
\end{tabular}

Table 11

Mean, standard deviation and CV of lead time demand of Segment 2 (Algeciras-Rotterdam).

\begin{tabular}{llcr}
\hline Speed (knots) & $\mu_{L_{S}^{i}}$ (FEUs) & $\sigma_{L_{S}^{i}}($ FEUs $)$ & $C V$ \\
\hline 22.0 & 657.3 & 123.0 & $18.7 \%$ \\
19.3 & 717.5 & 123.4 & $17.2 \%$ \\
17.1 & 794.7 & 126.7 & $15.9 \%$ \\
15.4 & 872.6 & 131.0 & $15.0 \%$ \\
14.0 & 951.5 & 135.6 & $14.3 \%$ \\
\hline
\end{tabular}

Table 12

Mean, standard deviation and CV of lead time demand of Segment 3 (Rotterdam-Oman).

\begin{tabular}{llcr}
\hline Speed (knots) & $\mu_{L_{S}^{i}}$ (FEUs) & $\sigma_{L_{S}^{i}}($ FEUs $)$ & $C V$ \\
\hline 22.0 & 26.7 & 6.8 & $25.5 \%$ \\
19.3 & 28.3 & 6.9 & $24.4 \%$ \\
17.1 & 31.3 & 7.0 & $22.4 \%$ \\
15.4 & 34.5 & 7.1 & $20.6 \%$ \\
14.0 & 37.4 & 7.2 & $19.3 \%$ \\
\hline
\end{tabular}

Table 13

Mean, standard deviation and CV of lead time demand of Segment 4.

\begin{tabular}{llcr}
\hline Speed (knots) & $\mu_{L_{S}^{i}}($ FEUs) & $\sigma_{L_{S}^{i}}($ FEUs $)$ & $C V$ \\
\hline 22.0 & 2215.9 & 420.7 & $19.0 \%$ \\
19.3 & 2350.3 & 421.2 & $17.9 \%$ \\
17.1 & 2611.8 & 425.1 & $16.3 \%$ \\
15.4 & 2896.0 & 433.1 & $15.0 \%$ \\
14.0 & 3151.1 & 444.5 & $14.1 \%$ \\
\hline
\end{tabular}

\subsection{Estimation of transportation costs}

The following two paragraphs discuss the estimation of the deep-sea shipping transportation costs as well as the logistics cost till the CDCs, respectively.

\subsubsection{Deep-sea shipping transportation costs per FEU}

The deep-sea shipping transportation costs per FEU are estimated based on Eq. (13), and given the transportation cost parameters 
Table 14

Deep-sea shipping transportation cost parameters for the voyage segments.

Source: Brouer et al. (2014), Searates.com and own input: A 1.14 Euro/USD exchange rate is considered.

\begin{tabular}{|c|c|}
\hline Parameters & Values \\
\hline Shanghai-Algeciras (nautical miles) & 9,116 \\
\hline Algeciras-Rotterdam (nautical miles) & 1,360 \\
\hline Rotterdam-Muscat (Oman) & 5,909 \\
\hline Muscat (Oman)-Shanghai & 5,308 \\
\hline Vessel's design $(d)$ speed (knots/hour)- $S_{d}$ & 17 \\
\hline Vessel's max speed (knots/hour)- $S_{m}$ & 22 \\
\hline Vessel's voyage fuel consumption at its design speed- $F_{d}$ (tons/day) & 126.9 \\
\hline Vessel's fuel consumption when idle (tons of fuel/day)-F & 10 \\
\hline Ship Operating Costs per Day (€/day)- $\mathrm{C}_{\mathrm{o}}$ & 49,107 \\
\hline Variable port-related costs per FEU, at Algeciras and Rotterdam (€/FEU/Voyage)- $P C_{V a r}=P C_{V a r_{2}}$ & 469 \\
\hline Variable port-related costs per FEU, at Muscat ( $€ / F E U /$ segment voyage)- $P C_{V a r}$ & 285 \\
\hline Variable port-related costs per FEU, at Shanghai (€/FEU/segment voyage)- $P C_{V r_{4}}$ & 647 \\
\hline Fixed port-related cost at the port of Shanghai, Algeciras, Rotterdam and Oman $\left(€ /\right.$ segment voyage)- $P C_{F_{1},}=P C_{F_{2},}=P C_{F_{3}}=P C_{F_{4}}$, & 25,402 \\
\hline Suez Canal Cost $(€ /$ segment voyage) & 462,222 \\
\hline IFO 180 bunker cost in Rotterdam $(€) /$ ton of fuel (19-6-2017/ http://shipandbunker.com/prices\#MGO)-FC & 221 \\
\hline$N_{1}, N_{2}$ (FEUs) & 6400 \\
\hline$N_{3}, N_{4}$ (FEUs) & 5600 \\
\hline
\end{tabular}

in each Segment 1-4, as illustrated in Table 14.

\subsubsection{Shipper's holding, backorder and operational costs per day at the CDC}

Given the refrigerator's net average value of $265 € /$ refrigerator and an annual target return on capital of $12 \%$ (Eefsen and Simonsen, 2010; Yin et al. 2014), the inventory holding cost per FEU per day is estimated as $h=(265 \cdot 39.8 \cdot 0.12) / 365=3.47 € / F E U /$ day. However, and as the pipeline inventory cost per FEU per day does not incorporate the facility-related operating costs, we further assume that it represents $80 \%$ of the inventory holding costs per FEU per day and is therefore equal to $h^{p}=2.78 € / \mathrm{FEU} / \mathrm{day}$. Regarding the CDC's back order cost value, $b$, we assume that this cost represents the shipper's loss of goodwill which due to the extensive competition in the white goods retail market, is estimated as $5 \%$ of the FEU's average net value, and is therefore equal to $0.05 \cdot 10,547=527.35 € /$ FEU stockout.

Finally, in order to determine the CDC's operating costs, we employed the logarithmic equation: $564.7 \cdot \ln \left(\mathrm{K}_{\mathrm{CDCi}}\right)-4112.9$ based on DC operating cost data provided by Mallidis et al. (2014), where $\mathrm{K}_{\mathrm{CDCi}}=100,000 \mathrm{~m}^{3}$.

\subsection{Numerical analysis}

We proceeded by estimating the cost impact of lower vessel speeds on the vessel's voyage costs and on the shipper's logistics costs in each segment. For each segment of the network, we solved five instances of Eq. (13) one for each effective speed of Table 8. Tables 15 and 16 capture the impact of slow steaming on the carrier's voyage and on the shipper's logistics costs per FEU considering a weekly service.

The results of Table 15 indicate that the impact of slow steaming on voyage cost reductions does not necessary increase as voyage transportation distances increase. These impacts depend on a breakpoint distance travelled that effectively balances the marginal operational cost increases under slow steaming, as voyage days increase, to the marginal fuel cost reductions as voyage speeds and thus voyage fuel consumption decreases. Thus, in the examined shipping network and under slow steaming, we observe that the highest voyage cost reduction of $792.9 €-757.8 €=35.1 €$ per FEU is achieved at the voyage distance of Segment $3(5,909 \mathrm{~km})$, even though it involves a significantly lower voyage distance compared to that of Segment $1(9,116 \mathrm{~km})$.

With respect to the Shipper, the impact of slow steaming on his total landed logistics costs are summarized in the following Table 16.

Table 15

Deep-sea shipping voyage costs per FEU for the four segments.

\begin{tabular}{llll}
\hline Speed (knots) & $\begin{array}{l}\text { Segment } 1 \\
(€ / \text { FEU) }\end{array}$ & $\begin{array}{l}\text { Segment 2 } \\
(€ / \text { FEU) }\end{array}$ & $\begin{array}{l}\text { Segment 3 } \\
(€ / \text { FEU) }\end{array}$ \\
\hline 22.0 & 852.2 & 598.8 & 792.9 \\
19.3 & $824.8(-3.22 \%)$ & $591.2(-1.27 \%)$ & $763.6(-3.70 \%)$ \\
17.1 & $815.4(-1.14 \%)$ & $588.5(-0.46 \%)$ & $755.1(-1.11 \%)$ \\
15.4 & $815.1(-0.04 \%)$ & $587.7(-0.14 \%)$ & $755.6(+0.07 \%)$ \\
14.0 & $820.9(+0.71 \%)$ & $587.9(+0.03 \%)$ & $757.8(+0.29 \%)$ \\
$C_{\text {Carrier }}^{-}$ & $852.2-820.9=31.3 €$ & $10.9 €$ & $735.5(-0.81 \%)$ \\
\hline
\end{tabular}

$\mathrm{C}_{\text {Carrier }}^{-}$: Carrier's voyage cost reduction per FEU from 22 to 14 knots 
Table 16

Shipper's total landed logistics costs per FEU for the four segments.

\begin{tabular}{|c|c|c|c|c|}
\hline \multirow[t]{2}{*}{ Speed (knots) } & \multicolumn{2}{|l|}{ Forward voyage } & \multicolumn{2}{|l|}{ Return voyage } \\
\hline & Segment 1 (€/FEU) & Segment 2 (€/FEU) & Segment 3 (€/FEU) & Segment $4(€ /$ FEU $)$ \\
\hline 22.0 & 201.9 & 219.0 & 181.5 & 225.7 \\
\hline 19.3 & 207.4 & 225.0 & 184.1 & 229.9 \\
\hline 17.1 & 215.6 & 233.8 & 187.9 & 238.3 \\
\hline 15.4 & 224.2 & 243.0 & 193.5 & 248.0 \\
\hline 14.0 & 233.0 & 252.5 & 198.7 & 257.1 \\
\hline $\mathrm{C}_{\text {Shipper }}^{+}$ & $(233-201.9)=31.1 €$ & $33.5 €$ & $17.2 €$ & $31.4 €$ \\
\hline
\end{tabular}

$\mathrm{C}_{\text {Shipper }}^{+}$: Shipper's total landed logistics costs increases per FEU from 22 to 14 knots.

An interesting finding derived from Table 16, shows that the impact of slow steaming on the shippers' cycle stock and pipeline inventory holding cost increases are becoming progressively higher as the vessel travels to the last segments of the voyage, due to the higher accumulated lead times that the shippers faces. Consequently, the shipper that utilizes the last segment of the voyage suffers the highest increases of his logistics costs.

The shippers' optimal values of the decision variables are depicted in Table 17.

The results of Table 17 clearly illustrate the opposed behavior of the safety stock factor and order batch size value for lower slow steaming speeds. This is due to the tendency of the inventory system to compensate for the changes in the CDC's service level Type I, derived from the lower safety stock factor, by adjusting the CDC's inventory level through changes in the order batch sizes. This further indicates that the evaluation of the impact of slow steaming on the shipper's inventory costs necessitates the joint optimization of both $z_{S}^{i}$ and $Q_{S}^{i}$ decision variables.

\subsubsection{Impact of reduced voyage duration variability}

The final step of our analysis involves the quantification of the cost impact of speed adjustments on the shipper's total landed logistics costs for the four Segments. In order to quantify this impact, we recalculated the shipper's logistics costs while considering the vessel's initial speed $(S)$ throughout the whole voyage, and thus the same voyage duration variability, for each slow steaming speed. Table 18 captures the differences in costs and the cost savings per FEU that the shipper enjoys through the reduced voyage variability that the carrier provides by adjusting speeds under slow steaming.

The results of Table 18 show that the impact of speed adjustments on the reduction of the shippers' lead time variability and thus safety stock holding costs, tends to increase as the vessel travels to the last segments of the roundtrip and thus, these positive impacts are accumulated. Consequently, the shipper that utilizes the last segment enjoys the higher benefits on his logistics costs.

\section{Summary and conclusions}

We present an analytical modelling methodology for assessing the impact of slow steaming on the carrier's voyage costs and on the shipper's total landed logistics costs across a container shipping line. We initially evaluate the distribution of the delays that could occur at the intermediate ports of call, based on historical delay data. These delays are then included in a new methodology for analytically estimating voyage times for each voyage segment and for various slow steaming speeds. This methodology includes an activity-based model for quantifying a vessel's voyage costs per container, and a continuous review inventory-planning model employed for quantifying a shipper's total landed logistics costs at the intermediate port of a shipping network. We applied the proposed methodology on a realistic global logistics network for an Asian white goods manufacturer that supplies the EU, and of a European machinery exporter, that supplies the Middle East and the Far East markets. The main insights obtained from our numerical analysis are summarized below:

As the vessel travels towards the last segment of a voyage the impact of slow steaming on the associated shippers' total landed

Table 17

Shipper's optimal decision variable values.

\begin{tabular}{|c|c|c|c|c|c|c|c|c|}
\hline \multirow{2}{*}{$\begin{array}{l}\text { Segments } \\
\text { Speed (knots) }\end{array}$} & \multicolumn{2}{|c|}{ Segment 1} & \multicolumn{2}{|c|}{ Segment 2} & \multicolumn{2}{|c|}{ Segment 3} & \multicolumn{2}{|c|}{ Segment 4} \\
\hline & $Q_{S}^{1}$ & $z_{s}^{1}$ & $Q_{s}^{2}$ & $z_{s}^{2}$ & $Q_{S}^{3}$ & $z_{s}^{3}$ & $Q_{S}^{4}$ & $z_{s}^{4}$ \\
\hline 22.0 & 15.3 & 2.067 & 73.7 & 2.002 & 3.9 & 2.116 & 254.4 & 1.970 \\
\hline 19.3 & 15.4 & 2.066 & 73.9 & 2.001 & 4.0 & 2.112 & 254.7 & 1.969 \\
\hline 17.1 & 16.0 & 2.050 & 76.2 & 1.988 & 4.0 & 2.112 & 257.4 & 1.965 \\
\hline 15.4 & 16.8 & 2.030 & 79.2 & 1.972 & 4.1 & 2.102 & 263.0 & 1.955 \\
\hline 14.0 & 17.6 & 2.009 & 82.4 & 1.955 & 4.2 & 2.089 & 271.0 & 1.943 \\
\hline
\end{tabular}

Note that $z_{s}^{1}, z_{s}^{2}, z_{s}^{3} \geqslant-0.5531$, and thus the first order conditions (Eqs. (11) and (12)) are satisfied. Moreover, the changes of the values of $Q_{S}^{i}$ represent changes in units of FEUs and are thus significant. 
Table 18

Impact of Speed Adjustments (S.A) to the Shipper's costs per FEU for the four segments.

\begin{tabular}{|c|c|c|c|c|c|c|c|c|}
\hline \multirow[t]{2}{*}{ Speed (knots) } & \multicolumn{2}{|c|}{$\begin{array}{l}\text { Segment } 1 \\
(€ / \text { FEU) }\end{array}$} & \multicolumn{2}{|c|}{$\begin{array}{l}\text { Segment } 2 \\
(€ / \mathrm{FEU})\end{array}$} & \multicolumn{2}{|c|}{$\begin{array}{l}\text { Segment } 3 \\
(€ / \mathrm{FEU})\end{array}$} & \multicolumn{2}{|c|}{$\begin{array}{l}\text { Segment } 4 \\
(€ / \text { FEU) }\end{array}$} \\
\hline & w S.A. & w/o S.A. & w S.A. & w/o S.A. & w S.A. & w/o S.A. & w S.A. & w/o S.A. \\
\hline 22.0 & 201.9 & 201.9 & 219.0 & 219.0 & 181.5 & 181.5 & 225.7 & 225.7 \\
\hline 19.3 & 207.4 & 209.2 & 225.0 & 226.5 & 184.1 & 184.6 & 229.9 & 230.9 \\
\hline 17.1 & 215.6 & 218.0 & 233.8 & 236.1 & 187.9 & 190.2 & 238.3 & 241.0 \\
\hline 15.4 & 224.2 & 226.7 & 243.0 & 245.7 & 193.5 & 196.3 & 248.0 & 251.8 \\
\hline 14.0 & 233.0 & 235.5 & 252.5 & 255.6 & 198.7 & 201.7 & 257.1 & 261.4 \\
\hline$€ / F E U$ & \multicolumn{2}{|c|}{$233-235.5=2.5 €$} & \multicolumn{2}{|l|}{$3.1 €$} & \multicolumn{2}{|l|}{$3.0 €$} & \multicolumn{2}{|l|}{$4.3 €$} \\
\hline
\end{tabular}

logistics costs increases are relatively higher, due to the higher accumulated lead times they face. Thus, the last shipper suffers the highest increases in his logistics costs.

The impact of speed adjustments on the reduction of the shippers' lead-time variability and thus safety stock holding costs tends to increase as the vessel moves to the end of the voyage, as these positive impacts are accumulated and thus, the last shipper enjoys the higher benefits in his logistics costs.

The safety stock factor and the order batch size values exhibit opposed behavior for lower slow steaming speeds. This is due to the tendency of the inventory system to compensate for the changes in the CDC's service level Type I, derived from the lower safety stock factor, by adjusting the CDC's inventory level through changes in the order batch sizes.

The impact of slow steaming on voyage cost reductions does not necessary increase as voyage transportation distances increase. These impacts depend on a breakpoint distance travelled that effectively balances the marginal operational cost increases under slow steaming, as voyage days increase, to the marginal fuel cost reductions as voyage speeds and thus voyage fuel increases.

As the reduction of the vessel's speed leads to a straightforward reduction of the vessel's fuel costs, and thus shipping $\mathrm{CO}_{2}$ emissions, slow steaming can significantly improve the shippers overall environmental footprint see for example (Zis et al. 2008).

\section{Appendix A. Proof of Proposition I}

In order to prove the convexity of Eq. (10), we need to jointly optimize the function's decision variables $\left(Q_{S}^{i}, z_{S}^{i}\right)$, and prove whether the following three Hessian global optimization conditions are satisfied:

For Normal Demand, and given that:

- $E\left(I L_{S}^{i}\right) \simeq \sigma_{L_{S}^{i} \cdot z_{S}^{i}}+\frac{Q_{S}^{i}}{2}$

- $E\left(B O_{S}^{i}\right)=\sigma_{L_{S}^{i}} \cdot\left[\varphi\left(z_{S}^{i}\right)-z_{S}^{i}\left(1-\Phi\left(z_{S}^{i}\right)\right)\right]$

- $K_{S}^{i}=\sigma_{L_{S}^{i}} \cdot z_{S}^{i}+Q_{S}^{i}$,

- $E\left(T C\left(Q_{S}^{i}, z_{S}^{i}\right)\right)=h \cdot E\left(I L_{S}^{i}\right)+b \cdot\left(\mu_{i} / Q_{S}^{i}\right) \cdot E\left(B O_{S}^{i}\right)+C_{D_{i}} \cdot \mu_{i}+h^{p} \cdot \mu_{L_{S}^{i}}+\left(K_{S}^{i} / K_{C D C_{i}}\right) \cdot C_{K_{C D C_{i}}}$

the following three (3) conditions must be satisfied:

Condition 1: $d^{2} E\left(T C\left(\mathrm{Q}_{S}^{\mathrm{i}}, \mathrm{z}_{S}^{\mathrm{i}}\right)\right) / d\left(\mathrm{z}_{S}^{\mathrm{i}}\right)^{2} \geqslant 0$

$$
\begin{aligned}
& \frac{d E\left(T C\left(Q_{S}^{i}, z_{S}^{i}\right)\right.}{d z_{S}^{i}}=h \cdot \frac{d E\left(I L_{S}^{i}\right)}{d z_{S}^{i}}+b \frac{\mu_{i}}{Q_{S}^{i}} \cdot \frac{d E\left(B O_{S}^{i}\right)}{d z_{S}^{i}}+\frac{d\left(K_{S}^{i}\right)}{d z_{S}^{i}} \cdot \frac{\mathrm{C}_{C D C_{i}}}{\mathrm{~K}_{C D C_{i}}}+\frac{d h^{p} \mu_{L_{S_{1}}}}{d z_{S}^{i}} \\
& =h \cdot \sigma_{L_{S}^{i}}+\frac{b \cdot \mu_{i} \cdot \sigma_{L_{S_{1}}}}{Q_{S}^{i}} \cdot\left(-z_{S}^{i} \cdot \varphi\left(z_{S}^{i}\right)-1+\Phi\left(z_{S}^{i}\right)+z_{S}^{i} \cdot \varphi\left(z_{S}^{i}\right)\right)+\frac{\sigma_{L_{S}^{i}} \cdot C_{\mathrm{K}_{C D C_{i}}}}{\mathrm{~K}_{C D C_{i}}} \\
& =h \cdot \sigma_{L_{S}^{i}}+\frac{b \cdot \mu_{i} \cdot \sigma_{L_{S}}}{Q_{S}^{i}} \cdot\left(\Phi\left(z_{S}^{i}\right)-1\right)+\frac{\sigma_{L_{S}^{i}} \cdot C_{\mathrm{K}_{C D C_{i}}}}{\mathrm{~K}_{C D C_{i}}} . \\
& \frac{d^{2} E\left(T C\left(Q_{S}^{i}, z_{S}^{i}\right)\right.}{d\left(z_{S}^{i}\right)^{2}}=\frac{b \cdot \mu_{i} \cdot \sigma_{L_{S}}}{Q_{S}^{i}} \cdot \varphi\left(z_{S}^{i}\right) \geqslant 0 .
\end{aligned}
$$

Condition 2: $d^{2} E\left(T C\left(Q_{S}^{i}, z_{S}^{i}\right)\right) / d\left(Q_{S}^{i}\right)^{2} \geqslant 0$

$$
\frac{d E\left(\left(T C\left(Q_{S}^{i}, z_{S}^{i}\right)\right)\right.}{d Q_{S}^{i}}=h \cdot \frac{d E\left(I L_{S}^{i}\right)}{d Q_{S}^{i}}+d \frac{b \cdot \frac{\mu_{i}}{Q_{S}^{i}} \cdot E\left(B O_{S}^{i}\right)}{d Q_{S}^{i}}+\frac{d\left(K_{S}^{i}\right)}{d Q_{S}^{i}} \cdot \frac{\mathrm{C}_{\mathrm{K}_{C D C_{i}}}}{\mathrm{~K}_{C D C_{i}}}+\frac{d h^{p} \cdot \mu_{L_{S}}}{d Q_{S}}
$$




$$
\begin{aligned}
& =\frac{h}{2}-\frac{b \cdot \mu_{i} \cdot \sigma_{L_{S}^{i}}\left(\varphi\left(z_{S}^{i}\right)-z_{S}^{i}\left(1-\Phi\left(z_{S}^{i}\right)\right)\right)}{Q_{S}^{i^{2}}}+\frac{\mathrm{C}_{\mathrm{K}_{C D C_{i}}}}{\mathrm{~K}_{C D C_{i}}} . \\
& \frac{d^{2} E\left(T C\left(Q_{S}^{i},\right)\right)}{d\left(Q_{S}^{i}\right)^{2}}=\frac{2 \cdot b \cdot \mu_{i} \cdot \sigma_{L_{S}^{i}}}{Q_{S}^{i^{3}}} \cdot\left(\varphi\left(z_{S}^{i}\right)-z_{S}^{i}\left(1-\Phi\left(z_{S}^{i}\right)\right)\right) .
\end{aligned}
$$

As $2 b \mu_{i} \sigma_{L_{S}^{i}} / Q_{S_{1}}>0$, the second condition is satisfied for any value of $\mathrm{z}_{S}^{\mathrm{i}}$ that satisfies constraint $(\mathrm{A}):\left(\varphi\left(z_{S}^{i}\right)-z_{S}^{i}\left(1-\Phi\left(z_{S}^{i}\right)\right)\right) \geqslant 0$. Through standard numerical procedures, the analysis of the term $\left(\varphi\left(z_{S}^{i}\right)-z_{S}^{i}\left(1-\Phi\left(z_{S}^{i}\right)\right)\right)$ shows that it approaches zero from above. That is, it remains always positive for any value of $z_{S}^{i}$. This is also clearly shown in Fig. 3, which illustrates the behavior of constraint (A), that moves asymptotically to zero for any value of $z_{S}^{i}$.

Condition 3:

$$
\begin{aligned}
& \frac{d^{2} E\left(T C\left(\mathrm{Q}_{S}^{\mathrm{i}}, \mathrm{z}_{S}^{\mathrm{i}}\right)\right)}{d\left(\mathrm{z}_{S}^{\mathrm{i}}\right)^{2}} \cdot \frac{d^{2} E\left(T C\left(\mathrm{Q}_{S}^{\mathrm{i}}, \mathrm{z}_{S}^{\mathrm{i}}\right)\right)}{d\left(\mathrm{Q}_{S}^{\mathrm{i}}\right)^{2}}-\left[\frac{d^{2} E\left(T C\left(\mathrm{Q}_{S}^{\mathrm{i}}, \mathrm{z}_{S}^{\mathrm{i}}\right)\right)}{d \mathrm{Q}_{S}^{\mathrm{i}} d \mathrm{z}_{S}^{\mathrm{i}}}\right]^{2} \geqslant 0 \\
& \frac{d^{2} E\left(T C\left(Q_{S}^{i}, \mathrm{z}_{S}^{\mathrm{i}}\right)\right.}{d\left(z_{S}^{i}\right)^{2}} \cdot \frac{d^{2} E\left(T C\left(\left(Q_{S}^{i}, \mathrm{z}_{S}^{\mathrm{i}}\right)\right)\right.}{d\left(Q_{S}^{i}\right)^{2}}-\left[\frac{d^{2} E\left(T C\left(\left(Q_{S}^{i}, \mathrm{z}_{S}^{\mathrm{i}}\right)\right)\right.}{\left.d Q_{S}^{i} d z_{S}^{i}\right]}\right]^{2} \\
& \left.\left.=\frac{b \cdot \varphi\left(z_{S}^{i}\right) \cdot \mu_{i} \cdot \sigma_{L_{S}^{i}}}{Q_{S}^{i}} \cdot \frac{2 b \cdot \mu_{i} \cdot \sigma_{L_{S}^{i}}\left(\varphi\left(z_{S}^{i}\right)-z_{S}^{i}\left(1-\Phi\left(z_{S}^{i}\right)\right)\right)}{Q_{S}^{i^{3}}}\right]\right]^{2} \\
& -\left[\frac{d}{d Q_{S}^{i}}\left[\frac{d E\left(T C\left(Q_{S}^{i}, z_{S}^{i}\right)\right.}{d z_{S}^{i}}\right]\right. \\
& =\frac{2 \cdot\left(b \cdot \mu_{i} \cdot \sigma_{L_{S}}\right)^{2}}{Q_{S}^{i^{4}}} \cdot \varphi\left(z_{S}^{i}\right) \cdot\left(\varphi\left(z_{S}^{i}\right)-z_{S}^{i}\left(1-\Phi\left(z_{S}^{i}\right)\right)\right)-\left[\frac{d}{d Q_{S}^{i}}\left[\frac{d E\left(T C\left(Q_{S}^{i}, z_{S}^{i}\right)\right.}{d z_{S}^{i}}\right]\right]^{2} \\
& =\frac{2 \cdot\left(\mathrm{b} \cdot \mu_{i} \sigma_{L_{S}^{i}}\right)^{2}}{Q_{S}^{i^{4}}} \cdot \varphi\left(z_{S}^{i}\right) \cdot\left(\varphi\left(z_{S}^{i}\right)-z_{S}^{i}\left(1-\Phi\left(z_{S}^{i}\right)\right)\right) \\
& -\left[\frac{b \cdot \mu_{i} \cdot \sigma_{L_{S}^{i}} \cdot\left(\Phi\left(z_{S}^{i}\right)-1\right)}{Q_{S}^{i^{2}}}\right]^{2}
\end{aligned}
$$

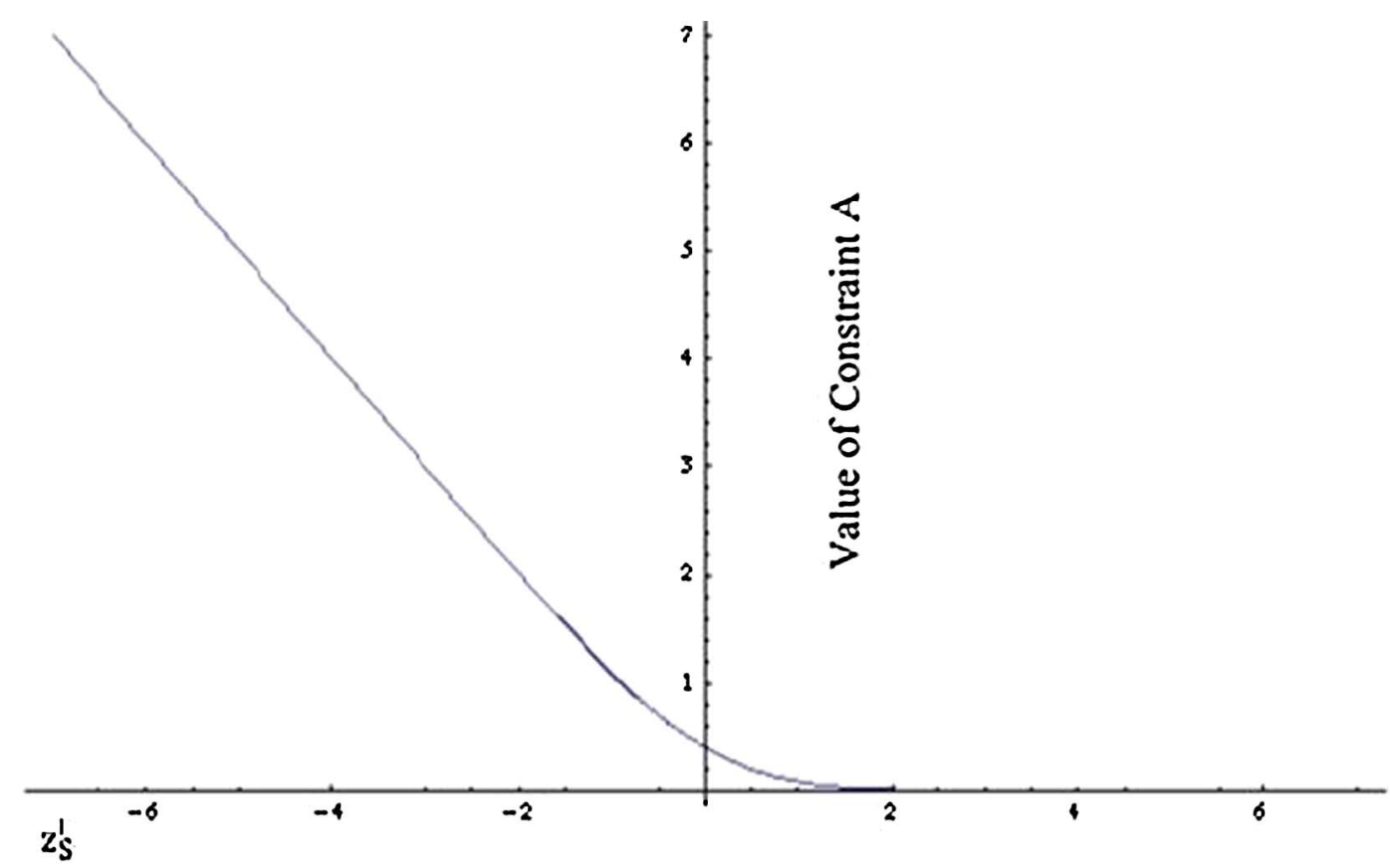

Fig. 3. Behavior of Constraint (A) for various values of $z_{S}^{i}$. 


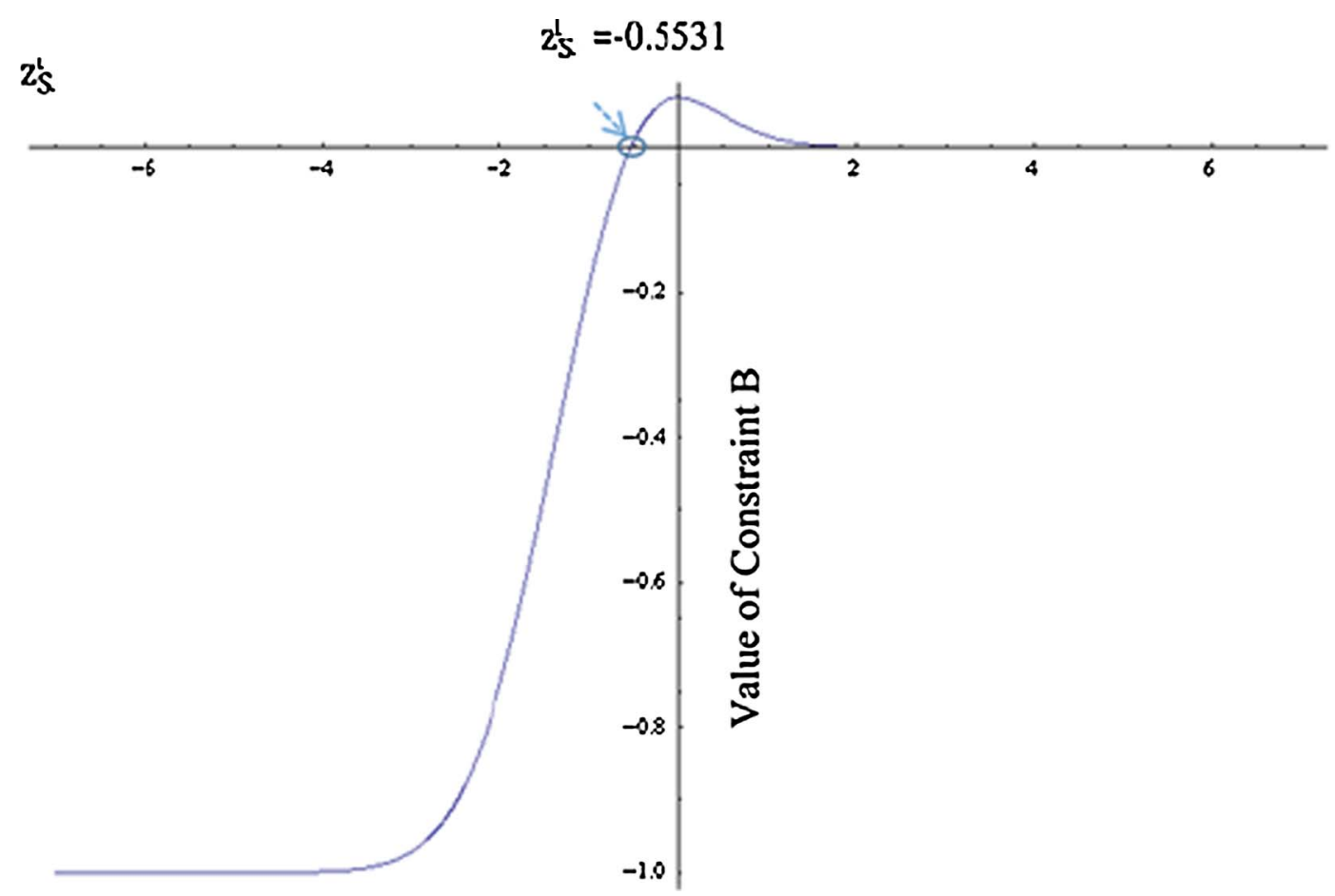

Fig. 4. Behavior of Constraint (B) for various values of $z_{S}^{i}$.

$$
\begin{aligned}
& =\frac{2 \cdot\left(b \cdot \mu_{i} \cdot \sigma_{L_{S}^{i}}\right)^{2}}{Q_{S}^{i^{4}}} \cdot \varphi\left(z_{S}^{i}\right) \cdot\left(\varphi\left(z_{S}^{i}\right)-z_{S}^{i}\left(1-\Phi\left(z_{S}^{i}\right)\right)\right) \\
& -\frac{\left(b \cdot \mu_{i} \cdot \sigma_{L_{S}^{i}}\right)^{2} \cdot\left(\Phi\left(z_{S}^{i}\right)-1\right)^{2}}{Q_{S}^{i^{4}}} \\
& =\frac{\left(b \cdot \mu_{i} \cdot \sigma_{L_{S}^{i}}\right)^{2}}{Q_{S}^{i^{4}}} \cdot\left(2 \cdot \varphi\left(z_{S}^{i}\right) \cdot\left(\varphi\left(z_{S}^{i}\right)-z_{S}^{i}\left(1-\Phi\left(z_{S}^{i}\right)\right)\right)-\left(\Phi\left(z_{S}^{i}\right)-1\right)^{2}\right)
\end{aligned}
$$

As $\frac{\left(\mathrm{b} \cdot \mu_{\mathrm{i}} \cdot \sigma_{\mathrm{L}}^{\mathrm{i}}\right)^{2}}{Q_{S}^{i^{4}}}$ is always positive, the third condition is satisfied for any value of $\mathrm{z}_{\mathrm{S}_{1}}$ that satisfies constraint (B): $\left[2 \varphi\left(z_{S}^{i}\right) \cdot\left(\varphi\left(z_{S}^{i}\right)-z_{S}^{i}\left(1-\Phi\left(z_{S}^{i}\right)\right)\right)-\left(\Phi\left(z_{S}^{i}\right)-1\right)^{2}\right] \geqslant 0$. Through standard numerical procedures, the analysis of the term $\left[2 \varphi\left(z_{S}^{i}\right) \cdot\left(\varphi\left(z_{S}^{i}\right)-\left(1-\Phi\left(z_{S}^{i}\right)\right)\right)-\left(\Phi\left(z_{S}^{i}\right)-1\right)^{2}\right]$ shows that it remains always positive for any value of $z_{S}^{i} \geqslant-0.5531$. This is also clearly shown in Fig. 4, which illustrates the behavior of constraint (B) for various values of $z_{S}^{i}$.

\section{Appendix B. Number of refrigerators per FEU}

In order to express the shipper's demand in FEUs, we need to be able determine the number of refrigerators that fit in one FEU. Thus, an average volume per refrigerator is required. We therefore employed the dimensions' data of various type of refrigerators provided by the website of Rempros (2016). Assuming that the sales of each refrigerator type exhibit the same proportion to the company's total refrigerator sales, we derived an average refrigerator volume of $0.90 \mathrm{~m}^{3}$ per refrigerator. Table 19 summarizes the dimension data of the examined refrigerators.

However, and as the shipping of the refrigerators requires additional packaging space, for each refrigerator type of Table 19, we added on average, an additional $0.1143 \mathrm{~m}$ space requirement in height, and $0.089 \mathrm{~m}$ in width and depth. We then re-estimated the average shipping volume per refrigerator which is equal to $1.19 \mathrm{~m}^{3}$. To this end, in order to determine the number of refrigerators that can fit in an FEU, we considered the volume of an FEU $=67.7 \mathrm{~m}^{3}$, an average loading rate per FEU $=70 \%$ (Eefsen and Simonsen, 2010; Yin et al., 2014), and the average shipping volume per refrigerator of $1.19 \mathrm{~m}^{3}$, leading to an average number of 39.8 refrigerators per FEU. 
Table 19

Average volume per refrigerator.

\begin{tabular}{|c|c|c|c|c|}
\hline Freezer- refrigerator Type & Width (m) & Height (m) & Depth (m) & Volume $\left(\mathrm{m}^{3}\right)$ \\
\hline Top mounted & 0.749 & 1.689 & 0.7145 & 0.904 \\
\hline Bottom & 0.822 & 1.715 & 0.7650 & 1.079 \\
\hline French door bottom & 0.823 & 1.728 & 0.8035 & 1.142 \\
\hline French door side by side & 0.835 & 1.727 & 0.8030 & 1.158 \\
\hline Compact & 0.483 & 0.641 & 0.5525 & 0.171 \\
\hline Average & & & & 0.90 \\
\hline
\end{tabular}

\section{Appendix C. Expected voyage duration cases of segments 3 and 4}

See Tables 20 and 21.

Table 20

Expected voyage duration cases for Segment 3.

\begin{tabular}{|c|c|}
\hline Cases & Expected voyage duration $E\left({ }^{c} T_{3}^{S}\right)$ \\
\hline $\begin{aligned} r_{1} & \leqslant \Delta_{1} \\
r_{2}^{\prime} & \leqslant \Delta_{2} \\
r_{3}^{\prime} & \leqslant \Delta_{3}\end{aligned}$ & $\int_{0}^{\Delta_{1}} \int_{0}^{\Delta_{2}} \int_{0}^{\Delta_{3}}\left(\frac{D_{3}}{S_{3}}+r_{3}\right) \cdot f_{R_{3}}\left(r_{3}\right) d r_{3} f_{R_{2}}\left(r_{2}\right) d r_{2} f_{R_{1}}\left(r_{1}\right) d r_{1}$ \\
\hline $\begin{aligned} r_{1} & \leqslant \Delta_{1} \\
& r_{2}^{\prime}>\Delta_{2} \\
& r_{3}^{\prime} \leqslant \Delta_{3}\end{aligned}$ & $\int_{0}^{\Delta_{1}} \int_{\Delta_{2}}^{\Delta_{2}+\Delta_{3}} \int_{0}^{\Delta_{3}+\Delta_{2}-r_{2}}\left(\frac{D_{3}}{S_{3}}+r_{3}\right) \cdot f_{R_{3}}\left(r_{3}\right) d r_{3} f_{R_{2}}\left(r_{2}\right) d r_{2} f_{R_{1}}\left(r_{1}\right) d r_{1}$ \\
\hline $\begin{aligned} & r_{1}>\Delta_{1} \\
& r_{2}^{\prime} \leqslant \Delta_{2} \\
& r_{3}^{\prime} \leqslant \Delta_{3}\end{aligned}$ & $\int_{\Delta_{1}}^{\Delta_{1}+\Delta_{2}} \int_{0}^{\Delta_{1}+\Delta_{2}-r_{1}} \int_{0}^{\Delta_{3}}\left(\frac{D_{3}}{S_{3}}+r_{3}\right) \cdot f_{R_{3}}\left(r_{3}\right) d r_{3} f_{R_{2}}\left(r_{2}\right) d r_{2} f_{R_{1}}\left(r_{1}\right) d r_{1}$ \\
\hline $\begin{aligned} r_{1} & >\Delta_{1} \\
r_{2}^{\prime} & >\Delta_{2} \\
r_{3}^{\prime} & \leqslant \Delta_{3}\end{aligned}$ & $\int_{\Delta_{1}}^{\Delta_{1}+\Delta_{2}+\Delta_{3}} \int_{\Delta_{1}+\Delta_{2}-r_{1}}^{\Delta_{1}+\Delta_{2}+\Delta_{3}-r_{1}} \int_{0}^{\Delta_{1}+\Delta_{2}+\Delta_{3}-r_{1}-r_{2}}\left(\frac{D_{3}}{S_{3}}+r_{3}\right) \cdot f_{R_{3}}\left(r_{3}\right) d r_{3} f_{R_{2}}\left(r_{2}\right) d r_{2} f_{R_{1}}\left(r_{1}\right) d r_{1}$ \\
\hline $\begin{aligned} r_{1} & \leqslant \Delta_{1} \\
r_{2}^{\prime} & \leqslant \Delta_{2} \\
r_{3}^{\prime} & >\Delta_{3}\end{aligned}$ & $\int_{0}^{\Delta_{1}} \int_{0}^{\Delta_{2}} \int_{\Delta_{3}}^{\infty}\left(\frac{D_{3}}{S_{m}}+r_{3}\right) \cdot f_{R_{3}}\left(r_{3}\right) d r_{3} f_{R_{2}}\left(r_{2}\right) d r_{2} f_{R_{1}}\left(r_{1}\right) d r_{1}$ \\
\hline $\begin{aligned} r_{1} & \leqslant \Delta_{1} \\
& r_{2}^{\prime}>\Delta_{2} \\
& r_{3}^{\prime}>\Delta_{3}\end{aligned}$ & $\int_{0}^{\Delta_{1}} \int_{\Delta_{2}}^{\infty} \int_{\Delta_{2}+\Delta_{3}-r_{2}}^{\infty}\left(\frac{D_{3}}{S_{m}}+r_{3}\right) \cdot f_{R_{3}}\left(r_{3}\right) d r_{3} f_{R_{2}}\left(r_{2}\right) d r_{2} f_{R_{1}}\left(r_{1}\right) d r_{1}$ \\
\hline $\begin{aligned} & r_{1}>\Delta_{1} \\
& r_{2}^{\prime} \leqslant \Delta_{2} \\
& r_{3}^{\prime}>\Delta_{3}\end{aligned}$ & $\int_{\Delta_{1}}^{\Delta_{1}+\Delta_{2}} \int_{0}^{\Delta_{1}+\Delta_{2}-r_{1}} \int_{\Delta_{3}}^{\infty}\left(\frac{D_{3}}{S_{m}}+r_{3}\right) \cdot f_{R_{3}}\left(r_{3}\right) d r_{3} f_{R_{2}}\left(r_{2}\right) d r_{2} f_{R_{1}}\left(r_{1}\right) d r_{1}$ \\
\hline $\begin{aligned} r_{1} & >\Delta_{1} \\
r_{2}^{\prime} & >\Delta_{2} \\
r_{3}^{\prime} & >\Delta_{3}\end{aligned}$ & $\int_{\Delta_{1}}^{\infty} \int_{\Delta_{1}+\Delta_{2}-r_{1}}^{\infty} \int_{\Delta_{1}+\Delta_{2}+\Delta_{3}-r_{2}-r_{1}}^{\infty}\left(\frac{D_{3}}{S_{m}}+r_{3}\right) \cdot f_{R_{3}}\left(r_{3}\right) d r_{3} f_{R_{2}}\left(r_{2}\right) d r_{2} f_{R_{1}}\left(r_{1}\right) d r_{1}$ \\
\hline
\end{tabular}


Table 21

Expected voyage duration cases for Segment 4.

\begin{tabular}{|c|c|}
\hline Cases & Expected voyage duration $E\left({ }^{c} T_{4}^{S}\right)$ \\
\hline $\begin{aligned} r_{1} & \leqslant \Delta_{1} \\
r_{2}^{\prime} & \leqslant \Delta_{2} \\
r_{3}^{\prime} & \leqslant \Delta_{3} \\
r_{4}^{\prime} & \leqslant \Delta_{4}\end{aligned}$ & $\int_{0}^{\Delta_{1}} \int_{0}^{\Delta_{2}} \int_{0}^{\Delta_{3}} \int_{0}^{\Delta_{4}}\left(\frac{D_{4}}{S_{4}}+r_{4}\right) \cdot f\left(r_{4}\right) d r_{4} f_{R_{3}}\left(r_{3}\right) d r_{3} f_{R_{2}}\left(r_{2}\right) d r_{2} f_{R_{1}}\left(r_{1}\right) d r_{1}$ \\
\hline $\begin{aligned} r_{1} & \leqslant \Delta_{1} \\
r_{2}^{\prime} & >\Delta_{2} \\
r_{3}^{\prime} & \leqslant \Delta_{3} \\
r_{4}^{\prime} & \leqslant \Delta_{4}\end{aligned}$ & $\int_{0}^{\Delta_{1}} \int_{\Delta_{2}}^{\Delta_{2}+\Delta_{3}} \int_{0}^{\Delta_{2}+\Delta_{3}-r_{2}} \int_{0}^{\Delta_{4}}\left(\frac{D_{4}}{S_{4}}+r_{4}\right) \cdot f\left(r_{4}\right) d r_{4} f_{R_{3}}\left(r_{3}\right) d r_{3} f_{R_{2}}\left(r_{2}\right) d r_{2} f_{R_{1}}\left(r_{1}\right) d r_{1}$ \\
\hline $\begin{aligned} r_{1} & \leqslant \Delta_{1} \\
r_{2}^{\prime} & \leqslant \Delta_{2} \\
r_{3}^{\prime} & >\Delta_{3} \\
r_{4}^{\prime} & \leqslant \Delta_{4}\end{aligned}$ & $\int_{0}^{\Delta_{1}} \int_{0}^{\Delta_{2}} \int_{\Delta_{3}}^{\Delta_{3}+\Delta_{4}} \int_{0}^{\Delta_{3}+\Delta_{4}-r_{3}}\left(\frac{D_{4}}{S_{4}}+r_{4}\right) \cdot f\left(r_{4}\right) d r_{4} f_{R_{3}}\left(r_{3}\right) d r_{3} f_{R_{2}}\left(r_{2}\right) d r_{2} f_{R_{1}}\left(r_{1}\right) d r_{1}$ \\
\hline $\begin{aligned} r_{1} & \leqslant \Delta_{1} \\
r_{2}^{\prime} & >\Delta_{2} \\
r_{3}^{\prime} & >\Delta_{3} \\
r_{4}^{\prime} & \leqslant \Delta_{4}\end{aligned}$ & $\int_{0}^{\Delta_{1}} \int_{\Delta_{2}}^{\Delta_{2}+\Delta_{3}+\Delta_{4}} \int_{\Delta_{2}+\Delta_{3}-\mathrm{r}_{2}}^{\Delta_{2}+\Delta_{3}+\Delta_{4}-\mathrm{r}_{2}} \int_{0}^{\Delta_{2}+\Delta_{3}+\Delta_{4}-\mathrm{r}_{2}-\mathrm{r}_{3}}\left(\frac{D_{4}}{S_{4}}+r_{4}\right) \cdot f\left(r_{4}\right) d r_{4} f_{R_{3}}\left(r_{3}\right) d r_{3} f_{R_{2}}\left(r_{2}\right) d r_{2} f_{R_{1}}\left(r_{1}\right) d r_{1}$ \\
\hline $\begin{aligned} r_{1} & >\Delta_{1} \\
& r_{2}^{\prime} \leqslant \Delta_{2} \\
& r_{3}^{\prime} \leqslant \Delta_{3} r_{4}^{\prime} \leqslant \Delta_{4}\end{aligned}$ & $\int_{\Delta_{1}}^{\Delta_{1}+\Delta_{2}} \int_{0}^{\Delta_{1}+\Delta_{2}-r_{1}} \int_{0}^{\Delta_{3}} \int_{0}^{\Delta_{4}}\left(\frac{D_{4}}{S_{4}}+r_{4}\right) \cdot f\left(r_{4}\right) d r_{4} f_{R_{3}}\left(r_{3}\right) d r_{3} f_{R_{2}}\left(r_{2}\right) d r_{2} f_{R_{1}}\left(r_{1}\right) d r_{1}$ \\
\hline $\begin{aligned} & r_{1}>\Delta_{1} r_{2}^{\prime}>\Delta_{2} \\
& r_{3}^{\prime} \leqslant \Delta_{3} \\
& r_{4}^{\prime} \leqslant \Delta_{4}\end{aligned}$ & $\int_{\Delta_{1}}^{\Delta_{1}+\Delta_{2}+\Delta_{3}} \int_{\Delta_{1}+\Delta_{2}-r_{1}}^{\Delta_{1}+\Delta_{2}+\Delta_{3}-r_{1}} \int_{0}^{\Delta_{1}+\Delta_{2}+\Delta_{3}-r_{1}-r_{2}} \int_{0}^{\Delta_{4}}\left(\frac{D_{4}}{S_{4}}+r_{4}\right) \cdot f\left(r_{4}\right) d r_{4} f_{R_{3}}\left(r_{3}\right) d r_{3} f_{R_{2}}\left(r_{2}\right) d r_{2} f_{R_{1}}\left(r_{1}\right) d r_{1}$ \\
\hline $\begin{array}{l}r_{1}>\Delta_{1} r_{2}^{\prime} \leqslant \Delta_{2} \\
r_{3}^{\prime}>\Delta_{3} \\
r_{4}^{\prime} \leqslant \Delta_{4}\end{array}$ & $\int_{\Delta_{1}}^{\Delta_{1}+\Delta_{2}} \int_{0}^{\Delta_{1}+\Delta_{2}-r_{1}} \int_{\Delta_{3}}^{\Delta_{3}+\Delta_{4}} \int_{0}^{\Delta_{4}+\Delta_{3}-r_{3}}\left(\frac{D_{4}}{S_{4}}+r_{4}\right) \cdot f\left(r_{4}\right) d r_{4} f_{R_{3}}\left(r_{3}\right) d r_{3} f_{R_{2}}\left(r_{2}\right) d r_{2} f_{R_{1}}\left(r_{1}\right) d r_{1}$ \\
\hline $\begin{aligned} r_{1} & >\Delta_{1} \\
r_{2}^{\prime} & >\Delta_{2} \\
r_{3}^{\prime} & >\Delta_{3} \\
r_{4}^{\prime} & \leqslant \Delta_{4}\end{aligned}$ & $\int_{\Delta_{1}}^{\Delta_{1}+\Delta_{2}+\Delta_{3}+\Delta_{4}} \int_{\Delta_{2}+\Delta_{1}-r_{1}}^{\Delta_{1}+\Delta_{2}+\Delta_{3}+\Delta_{4}-r_{1}} \int_{\Delta_{3}+\Delta_{2}+\Delta_{1}-r_{2}-r_{1}}^{\Delta_{1}+\Delta_{2}+\Delta_{3}+\Delta_{4}-r_{1}-r_{2}} \int_{0}^{\Delta_{1}+\Delta_{2}+\Delta_{3}+\Delta_{4}-r_{1}-r_{2}-r_{3}}\left(\frac{D_{4}}{S_{4}}+r_{4}\right) \cdot f\left(r_{4}\right) d r_{4} f_{R_{3}}\left(r_{3}\right) d r_{3} f_{R_{2}}\left(r_{2}\right) d r_{2} f_{R_{1}}\left(r_{1}\right) d r_{1}$ \\
\hline $\begin{aligned} r_{1} & \leqslant \Delta_{1} \\
r_{2}^{\prime} & \leqslant \Delta_{2} \\
r_{3}^{\prime} & \leqslant \Delta_{3} \\
r_{4}^{\prime} & >\Delta_{4}\end{aligned}$ & $\int_{0}^{\Delta_{1}} \int_{0}^{\Delta_{2}} \int_{0}^{\Delta_{3}} \int_{\Delta_{4}}^{\infty}\left(\frac{D_{4}}{S_{m}}+r_{4}\right) \cdot f\left(r_{4}\right) d r_{4} f_{R_{3}}\left(r_{3}\right) d r_{3} f_{R_{2}}\left(r_{2}\right) d r_{2} f_{R_{1}}\left(r_{1}\right) d r_{1}$ \\
\hline $\begin{aligned} r_{1} & \leqslant \Delta_{1} \\
& r_{2}^{\prime}>\Delta_{2} \\
& r_{3}^{\prime} \leqslant \Delta_{3} \\
& r_{4}^{\prime}>\Delta_{4}\end{aligned}$ & $\int_{0}^{\Delta_{1}} \int_{\Delta_{2}}^{\Delta_{2}+\Delta_{3}} \int_{0}^{\Delta_{2}+\Delta_{3}-r_{2}} \int_{\Delta_{4}}^{\infty}\left(\frac{D_{4}}{S_{m}}+r_{4}\right) \cdot f\left(r_{4}\right) d r_{4} f_{R_{3}}\left(r_{3}\right) d r_{3} f_{R_{2}}\left(r_{2}\right) d r_{2} f_{R_{1}}\left(r_{1}\right) d r_{1}$ \\
\hline $\begin{aligned} r_{1} & \leqslant \Delta_{1} \\
r_{2}^{\prime} & \leqslant \Delta_{2} \\
r_{3}^{\prime} & >\Delta_{3} \\
r_{4}^{\prime} & >\Delta_{4}\end{aligned}$ & $\int_{0}^{\Delta_{1}} \int_{0}^{\Delta_{2}} \int_{\Delta_{3}}^{\infty} \int_{\Delta_{3}+\Delta_{4}-r_{3}}^{\infty}\left(\frac{D_{4}}{S_{m}}+r_{4}\right) \cdot f\left(r_{4}\right) d r_{4} f_{R_{3}}\left(r_{3}\right) d r_{3} f_{R_{2}}\left(r_{2}\right) d r_{2} f_{R_{1}}\left(r_{1}\right) d r_{1}$ \\
\hline $\begin{aligned} r_{1} & \leqslant \Delta_{1} \\
& r_{2}^{\prime}>\Delta_{2} \\
& r_{3}^{\prime}>\Delta_{3} \\
& r_{4}^{\prime}>\Delta_{4}\end{aligned}$ & $\int_{0}^{\Delta_{1}} \int_{\Delta_{2}}^{\infty} \int_{\Delta_{2}+\Delta_{3}-r_{2}}^{\infty} \int_{\Delta_{2}+\Delta_{3}+\Delta_{4}-r_{2}-r_{3}}^{\infty}\left(\frac{D_{4}}{S_{m}}+r_{4}\right) \cdot f\left(r_{4}\right) d r_{4} f_{R_{3}}\left(r_{3}\right) d r_{3} f_{R_{2}}\left(r_{2}\right) d r_{2} f_{R_{1}}\left(r_{1}\right) d r_{1}$ \\
\hline $\begin{array}{l}r_{1}>\Delta_{1} r_{2}^{\prime} \leqslant \Delta_{2} \\
r_{3}^{\prime} \leqslant \Delta_{3} \\
r_{4}^{\prime}>\Delta_{4}\end{array}$ & $\int_{\Delta_{1}}^{\Delta_{1}+\Delta_{2}} \int_{0}^{\Delta_{2}+\Delta_{1}-r_{1}} \int_{0}^{\Delta_{3}} \int_{\Delta_{4}}^{\infty}\left(\frac{D_{4}}{S_{m}}+r_{4}\right) \cdot f\left(r_{4}\right) d r_{4} f_{R_{3}}\left(r_{3}\right) d r_{3} f_{R_{2}}\left(r_{2}\right) d r_{2} f_{R_{1}}\left(r_{1}\right) d r_{1}$ \\
\hline $\begin{aligned} r_{1} & >\Delta_{1} \\
r_{2}^{\prime} & >\Delta_{2} \\
r_{3}^{\prime} & \leqslant \Delta_{3} \\
r_{4}^{\prime} & >\Delta_{4}\end{aligned}$ & $\int_{\Delta_{1}}^{\Delta_{1}+\Delta_{2}+\Delta_{3}} \int_{\Delta_{1}+\Delta_{2}-r_{1}}^{\Delta_{1}+\Delta_{2}+\Delta_{3}-r_{1}} \int_{0}^{\Delta_{1}+\Delta_{2}+\Delta_{3}-r_{2}-r_{1}} \int_{\Delta_{4}}^{\infty}\left(\frac{D_{4}}{S_{m}}+r_{4}\right) \cdot f\left(r_{4}\right) d r_{4} f_{R_{3}}\left(r_{3}\right) d r_{3} f_{R_{2}}\left(r_{2}\right) d r_{2} f_{R_{1}}\left(r_{1}\right) d r_{1}$ \\
\hline $\begin{aligned} r_{1} & >\Delta_{1} \\
r_{2}^{\prime} & \leqslant \Delta_{2} \\
r_{3}^{\prime} & >\Delta_{3} \\
r_{4}^{\prime} & >\Delta_{4}\end{aligned}$ & $\int_{\Delta_{1}}^{\Delta_{1}+\Delta_{2}} \int_{0}^{\Delta_{1}+\Delta_{2}-r_{1}} \int_{\Delta_{3}}^{\infty} \int_{\Delta_{4}+\Delta_{3}-r_{3}}^{\infty}\left(\frac{D_{4}}{S_{m}}+r_{4}\right) \cdot f\left(r_{4}\right) d r_{4} f_{R_{3}}\left(r_{3}\right) d r_{3} f_{R_{2}}\left(r_{2}\right) d r_{2} f_{R_{1}}\left(r_{1}\right) d r_{1}$ \\
\hline $\begin{aligned} r_{1} & >\Delta_{1} \\
r_{2}^{\prime} & >\Delta_{2} \\
r_{3}^{\prime} & >\Delta_{3} \\
r_{4}^{\prime} & >\Delta_{4}\end{aligned}$ & $\int_{\Delta_{1}}^{\infty} \int_{\Delta_{1}+\Delta_{2}-r_{1}}^{\infty} \int_{\Delta_{1}+\Delta_{2}+\Delta_{3}-r_{1}-r_{2}}^{\infty} \int_{\Delta_{1}+\Delta_{2}+\Delta_{3}+\Delta_{4}-r_{1}-r_{2}-r_{3}}^{\infty}\left(\frac{D_{4}}{S_{m}}+r_{4}\right) \cdot f\left(r_{4}\right) d r_{4} f_{R_{3}}\left(r_{3}\right) d r_{3} f_{R_{2}}\left(r_{2}\right) d r_{2} f_{R_{1}}\left(r_{1}\right) d r_{1}$ \\
\hline
\end{tabular}




\section{Appendix D. Total voyage delay allocation to the shipping network's entry ports}

See Tables 22-27.

Table 22

Distribution of vessel arrival delays.

\begin{tabular}{ll}
\hline Time intervals (days) & Observed frequency (No. of vessels) \\
\hline $0-1$ & 1,838 \\
$1-2$ & 465 \\
$2-3$ & 237 \\
$3-4$ & 120 \\
$4-5$ & 85 \\
$5-6$ & 41 \\
$6-7$ & 53 \\
$7-8$ & 41 \\
$8-9$ & 18 \\
$9-10$ & 15 \\
$10-11$ & 9 \\
Total & 2,919 \\
\hline
\end{tabular}

Table 23

CDF of the examined distributions and outputs of the Chi-square test

\begin{tabular}{|c|c|c|c|c|}
\hline Distrib. & $\mathrm{CDF}$ & Parameters & $x_{0}^{2}$ & $\mathrm{p}$-value \\
\hline Normal & $\frac{1}{2}\left[1+\operatorname{erf}\left(\frac{x-\mu}{\sigma \sqrt{2}}\right)\right]$ & 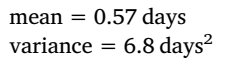 & 4944 & $100 \%$ \\
\hline Gamma & $\frac{\gamma(\mathrm{k}, \mathrm{x} / \theta)}{\Gamma(\mathrm{k})}$ & 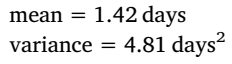 & 23 & $98.9 \%$ \\
\hline Weibull & $1-\mathrm{e}^{-\left(\frac{\mathrm{x}}{\lambda_{\mathrm{W}}}\right)^{K_{\mathrm{W}}}}: \mathrm{x} 0$ & 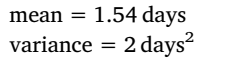 & 29 & $99.9 \%$ \\
\hline Lognorm. & $\frac{1}{2}\left[1+\operatorname{erf}\left(\frac{\ln (x)-\mu}{\sigma \sqrt{2}}\right)\right]$ & 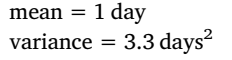 & 1778 & $100 \%$ \\
\hline Expon. & $1-\mathrm{e}^{-\lambda \mathrm{x}}: \mathrm{x} 0$ & mean $=0.62$ days & 69 & $100 \%$ \\
\hline
\end{tabular}

Table 24

Average vessel waiting times.

Source: Slack and Comptois, (2013).

\begin{tabular}{lll}
\hline Port & Ship Dwell Time (Days) & Percentage of total dwell time \\
\hline Route & East-Asia & $37 \%$ \\
Algeciras & 0.74 & $63 \%$ \\
Rotterdam & 1.24 & $57 \%$ \\
Route & Asia-Europe & $43 \%$ \\
Oman & 1.12 & \\
Shanghai & 0.85 & \\
\hline
\end{tabular}

Table 25

Mean and variance of the Gamma Distributed Delays.

\begin{tabular}{lll}
\hline Port & Mean delay (Days) & Variance of the delay (days ${ }^{2}$ ) \\
\hline Algeciras & 0.53 & 1.78 \\
Rotterdam & 0.89 & 3.03 \\
Oman & 0.81 & 2.74 \\
Shanghai & 0.61 & 2.07 \\
\hline
\end{tabular}


Table 26

Estimation of the $\kappa_{\gamma}$ and $\theta_{\gamma}$ parameters of the Gamma distribution.

\begin{tabular}{lll}
\hline $\begin{array}{l}\text { Parameters } \\
\text { Ports }\end{array}$ & Mean Delay (Days) & Variance of the delay (days ${ }^{2}$ ) \\
\hline Algeciras & $0.53=\kappa_{\gamma} \cdot \theta_{\gamma}$ & $1.78=\kappa_{\gamma} \cdot\left(\theta_{\gamma}\right)^{2}$ \\
Rotterdam & $0.89=\kappa_{\gamma} \cdot \theta_{\gamma}$ & $3.03=\kappa_{\gamma} \cdot\left(\theta_{\gamma}\right)^{2}$ \\
Oman & $0.81=\kappa_{\gamma} \cdot \theta_{\gamma}$ & $2.74=\kappa_{\gamma} \cdot\left(\theta_{\gamma}\right)^{2}$ \\
Shanghai & $0.61=\kappa_{\gamma} \cdot \theta_{\gamma}$ & $2.07=\kappa_{\gamma} \cdot\left(\theta_{\gamma}\right)^{2}$ \\
\hline
\end{tabular}

Table 27

Estimated $\kappa_{\gamma}$, and $\theta_{\gamma}$ parameter values for each port.

\begin{tabular}{llc}
\hline Port & Parameter $\kappa_{\gamma}$ & Parameter $\theta_{\gamma}$ \\
\hline Algeciras & 0.16 & 3.36 \\
Rotterdam & 0.26 & 3.40 \\
Oman & 0.24 & 3.38 \\
Shanghai & 0.18 & 3.39 \\
\hline
\end{tabular}

\section{References}

Adland, A., Fonnes, G., Jia, H., Lampe, O., Strandenes, S., 2017. The impact of regional environmental regulations on empirical vessel speeds. Transp. Res. Part D $37-49$.

Andersson, H., Fagerholt, K., Hobbesland, K., 2015. Integrated maritime fleet deployment and speed optimization: Case study from RoRo shipping. Comput. Oper. Res. $233-240$.

Aydin, N., Lee, H., Mansouri, S., 2017. Speed optimization and bunkering in liner shipping in the presence of uncertain service times and time windows at ports. Eur. J. Oper. Res. 143-154.

Brouer, B.D., Dirksen, J., Pisinger, D., Plum, C., Vaaben, B., 2013. The Vessel Schedule Recovery Problem (VSRP) - a MIP model for handling disruptions in liner shipping. Eur. J. Oper. Res. 362-374.

Brouer, B., Alvarez, J., Plum, C., Pisinger, D., Sigurd, M., 2014. A base integer programming model and benchmark suite for liner-shipping network design. Transp. Sci. 281-312.

Cariou, P., Cheaitou, A., 2012. The effectiveness of a European speed limit versus an international bunker-levy to reduce $\mathrm{CO}_{2}$ emissions from container shipping. Transp. Res. Part D 116-123.

Chang, C., Chang, C., 2013. Energy conservation for international dry bulk carriers via vessel speed reduction. Energy Policy, pp. 710-715.

Chang, C., Wang, C., 2014. Evaluating the effects of speed reduce for shipping costs and $\mathrm{CO}_{2}$ emission. Transp. Res. Part D 110-115.

Chopra, S., Meindl, P., 2004. Supply Chain Management: Strategy, Planning and Operation. Pearson Education, New Jersey.

Corbett, J., Wang, H., Winebrake, J., 2009. The effectiveness and costs of speed reductions on emissions from international shipping. Transp. Res. Part D 593-598.

Eefsen, T., Simonsen, B., 2010. Speed, Carbon Emissions and Supply Chain in Container Shipping. In: Proceedings of the International Association of Maritime Economists Conference, Lisbon.

Euromonitor International, 2016. Statistics: Refrigeration Appliances. Retrieved from Passport GMID, Euromonitor International: http://www.portal.euromonitor. com/portal/statistics/rankcountries.

Fagerholt, K., Gausel, N., Rakke, J., Psaraftis, H., 2015. Maritime routing and speed optimization with emission control areas. Transp. Res. Part C 57-73.

Fagerholt, K., Laporte, G., Norstad, I., 2010. Reducing fuel emissions by optimizing speed on shipping routes. J. Operat. Res. Soc. 523-529.

Fischer, A., Nokhart, H., Olsen, H., Fagerholt, K., Rakke, J., 2016. Robust planning and disruption management in roll-on roll-off liner shipping. Transp. Res. Part E 51-67.

Guericke, S., Tierney, K., 2015. Liner shipping cargo allocation with service levels and speed optimization. Transp. Res. Part E 40-60.

Haralambides, H., Thanopoulou, H., 2014. The Economic Crisis of 2008 and World Shipping: Unheeded Warnings. SPOUDAI J. Econ. Business.

Harrison, A., Fichtinger, J., 2013. Managing variability in ocean shipping. Int. J. Log. Manage. 24, 7-21.

Lee, C., Lee, H., Zhang, J., 2015. The impact of slow steaming on delivery reliability and fuel consumption. Transp. Res. Part E 76, 176-190.

Lee, H., Aydin, N., Choi, Y., Lekhavat, S., Irani, Z., 2017. A decision support system for vessel speed decision in maritime logistics using weather archive big data. Comput. Oper. Res. 1-13.

Li, C., Qi, X., Song, D., 2016. Real-time schedule recovery in liner shipping service with regular uncertainties and disruption events. Transp. Res. Part B 762-788.

Lindstad, H., Asbjørnslett, B., Strømman, A., 2011. Reductions in green house gas emissions and cost by shipping at lower speeds. Energy Policy $3456-3464$.

Maersk, 2017. AE10 Westbound. Retrieved from https://www.maerskline.com/routes/shipping-from-asia-to-europe/ae10-westbound.

Magirou, E., Psaraftis, H., Bouritas, T., 2015. The economic speed of an oceangoing vessel in a dynamic setting. Transp. Res. Part B 48-67.

Mallidis, I., Vlachos, D., Iakovou, E., Dekker, R., 2014. Design and planning for green global supply chains under periodic review replenishment policies. Transp. Res. Part E 210-235.

Maloni, M., Paul, J., Gligor, D., 2013. Slow steaming impacts on ocean carriers and shippers. Maritime Econ. Logist. 151-171.

Meng, Q., Wang, S., Andersson, H., Thun, K., 2014. Containership routing and scheduling in liner shipping: overview and future research directions. Transp. Sci. 48, 265-280.

Miche, A., Attali, S., Bush, E., 2015. Energy efficiency of White Goods in Europe: Monitoring the Market with Sales Data. Retrieved from http://www.topten.eu/ uploads/File/WhiteGoods in Europe_June15.pdf.

Norlund, E., Gribkovskaia, I., 2013. Reducing emissions through speed optimization in supply vessel operations. Transp. Res. Part D $105-113$.

Norlund, E., Gribkovskaia, I., Laporte, G., 2016. Supply vessel planning under cost, environment and robustness considerations. OMEGA 271-281.

Psaraftis, H., Kontovas, C., 2010. Balancing the economic and environmental performance of maritime transportation. Transp. Res. Part D 458-462.

Psaraftis, H., Kontovas, C., 2013. Speed models for energy-efficient maritime transportation: a taxonomy and survey. Transp. Res. Part C 331-351.

Psaraftis, H., Kontovas, C., 2014. Ship speed optimization: concepts, models and combined speed-routing scenarios. Transp. Res. Part C 52-69.

Rahman, N., Yang, Z., Bonsall, S., Wang, J., 2015. A fuzzy rule-based Bayesian reasoning method for analysing the necessity of super slow steaming under uncertainty: containership. Int. J. e-Navigat. Maritime Econ. 1-12.

Raunek, K., 2015. What is the Difference between Lay days and Lay time? Retrieved 2016, from Marine Insight: http://www.marineinsight.com/maritime-law/whatis-the-difference-between-lay-days-and-lay-time/. 
Rempros., 2016. Refrigerator Sizes. Retrieved from Remros Remodelling professionals: http://www.rempros.com/dimensions/refrigerator sizes.html.

Rodrigue, J., 2017. Fuel Consumption by Containership Size and Speed. Retrieved from. https://people.hofstra.edu/geotrans/eng/ch8en/conc8en/fuel_consumption containerships.html.

Sanguri, M., 2012. The Guide to slow Steaming on Ships. Retrieved from http://www.marineinsight.com/wp-content/uploads/2013/01/The-guide-to-slow-steamingon-ships.pdf.

Silver, A., Pyke, D., Peterson, R., 1998. Inventory Management and Production Planning and Scheduling, third ed. Willey, USA.

Slack, B., Comptois, C., 2013. http://imet.gr/Portals/0/Intranet/Proceedings/SIGA2/slack[1].pdf. Retrieved from http://imet.gr/Portals/0/Intranet/Proceedings/ SIGA2/slack[1].pdf.

Song, D., Li, D., Drake, P., 2015. Multi-objective optimization for planning liner shipping service with uncertain port times. Transp. Res. Part E 1-22.

Stopford, M., 2010. A Year of Decisions For Shipping -How Will The Markets Develop? Retrieved from A Year of Decisions in Shipping: http://www.clarksons.net/ archive/research/freestuff/MartinStopfordHowWilltheMarketDevelopSept102010(paper).pdf.

Tai, H., Lin, D., 2013. Comparing the unit emissions of daily frequency and slow steaming strategies on trunk route deployment ininternational container shipping. Transport. Res. Part D 26-31.

Tezdogan, T., Incecik, A., Turan, O., \& Kellet, P., 2014. Assessing the impact of a slow steaming approach on reducing the fuel consumption of a containership advancing in head seas. Transp. Res. Procedia, pp. 1659-1668.

UNCTAD, 2013. Review of Maritime Transport. Retrieved from. http://unctad.org/en/PublicationChapters/rmt2013ch3_en.pdf.

UNCTAD, 2016. Retrieved from Review of Maritime Transport: http://unctad.org/en/PublicationsLibrary/rmt2016 en.pdf.

Wang, C., Xu, C., 2015. Sailing speed optimization in voyage chartering ship considering. Comput. Ind. Eng. 108-115.

Wang, S., Meng, Q., 2012. Sailing speed optimization for container ships in a liner shipping network. Transp. Res. Part E 701-714.

Wen, H., Pacino, D., Kontovas, C., Psaraftis, H., 2017. A multiple ship routing and speed optimization problem under time, cost and environmental objectives. Transp. Res. Part D 303-321.

Wong, E., Tai, A., Lau, H., Raman, M., 2015. A utility-based decision support sustainability model in slow steaming maritime operations. Transp. Res. Part E 78, 57-69.

World Shipping Council, 2008. Retrieved from Record Fuel Prices Place Stress on Ocean Shipping: http://www.worldshipping.org/pdf/wsc_fuel_statement_final.pdf. Wu, W., 2009. An approach for measuring the optimal fleet capacity: evidence from the container shipping lines in Taiwan. Int. J. Prod. Econ. 118-126.

Yin, J., Fan, L., Yang, Z., Li, Y., 2014. Slow steaming of liner trade: its economic and environmental impacts. Maritime Policy Manage.

Zis, T., North, R., Angeloudis, P., Ochieng, W., Bell, M., 2008. Evaluation of cold ironing and speed reduction policies to reduce ship emissions near and at ports. Maritime Econ. Logist. 371-398. 